\title{
Effects of exercise on depression in adults with arthritis: a systematic review with meta-analysis of randomized controlled trials
}

\author{
George A Kelley ${ }^{1 *}$, Kristi S Kelley ${ }^{1}$ and Jennifer M Hootman²
}

\begin{abstract}
Introduction: Previous randomized controlled trials have led to conflicting findings regarding the effects of exercise on depressive symptoms in adults with arthritis and other rheumatic conditions (AORC). The purpose of this study was to use the meta-analytic approach to resolve these discrepancies.

Methods: The inclusion criteria were: (1) randomized controlled trials, (2) exercise (aerobic, strength training, or both) $\geq 4$ weeks, (3) comparative control group, (4) adults with osteoarthritis, rheumatoid arthritis, fibromyalgia or systemic lupus erythematosus, (5) published studies in any language since January 1, 1981 and (6) depressive symptoms assessed. Studies were located by searching 10 electronic databases, cross-referencing, hand searching and expert review. Dual-selection of studies and data abstraction was performed. Hedge's standardized mean difference effect size (g) was calculated for each result and pooled using random-effects models, an approach that accounts for heterogeneity. Non-overlapping 95\% confidence intervals (Cl) were considered statistically significant. Heterogeneity based on fixed-effect models was estimated using $Q$ and $P^{2}$ with alpha values $\leq 0.10$ for $Q$ considered statistically significant.
\end{abstract}

Results: Of the 500 citations reviewed, 2,449 participants (1,470 exercise, 979 control) nested within 29 studies were included. Length of training, reported as mean \pm standard deviation $( \pm S D)$ was $19 \pm 16$ weeks, frequency $4 \pm 2$ times per week and duration $34 \pm 17$ minutes per session. Overall, statistically significant exercise minus control group reductions were found for depressive symptoms ( $\mathrm{g}=-0.42,95 \% \mathrm{Cl},-0.58,-0.26, \mathrm{Q}=126.9, P<0.0001, P=73.2 \%)$. The number needed-to-treat was 7 ( $95 \%$ Cl, 6 to 11) with an estimated 3.1 million (95\% Cl, 2.0 to 3.7) United States adults not currently meeting physical activity guidelines improving their depressive symptoms if they began and maintained a regular exercise program. Using Cohen's $U_{3}$ Index, the percentile reduction was $16.4 \%$ (95\% Cl, $10.4 \%$ to $\left.21.9 \%\right)$. All studies were considered to be at high risk of bias with respect to blinding of participants and personnel to group assignment.

Conclusions: Exercise is associated with reductions in depressive symptoms among selected adults with AORC. A need exists for additional, well-designed and reported studies on this topic.

\section{Introduction}

Arthritis is a major public health problem among adults in the United States (US). Current US estimates place the prevalence of doctor-diagnosed arthritis at 55.2 million $(22.7 \%)$ adults [1], and is projected to increase to 67 million (25\%) adults by the year 2030 [2]. Not surprisingly, the costs associated with arthritis and other rheumatic conditions are substantial. In 2003, the total

\footnotetext{
* Correspondence: gkelley@hsc.wvu.edu

'Department of Biostatistics, Robert C. Byrd Health Sciences Center, School of Public Health, West Virginia University, Morgantown, WV 26506-9190, USA Full list of author information is available at the end of the article
}

costs associated with arthritis were estimated at $\$ 127.8$ billion, $\$ 80.8$ billion in direct costs and $\$ 47.0$ billion in indirect costs [3]. A common mental health problem among adults with arthritis is depression. For example, a recent study of 1,793 US adults 45 years of age and older with arthritis found that $18 \%$ had depression while only $51 \%$ sought help for their depression [4]. One potential non-pharmacologic intervention for reducing depressive symptoms in adults with arthritis is exercise. Unfortunately, the prevalence of exercise in adults with arthritis is low. For example, the percentage of adults with doctor-diagnosed arthritis who perform moderate physical activity for at least 
30 minutes per day, three days per week, has been reported to be only $37 \%$ [5]. In addition, previous randomized controlled trials that examined the effects of exercise (aerobic, strength training, or both) on depressive symptoms in adults with arthritis and other rheumatic conditions (AORC) have led to conflicting results [6-34] with 23 and 36 exercise versus control between-group differences reported as either statistically significant $[12-14,18,19,21,23,25,27-30,32,33]$ or null [6-11,15-18,20,22-24,26,31,34], respectively. While this may lead one to generally conclude that exercise does little to reduce depressive symptoms in adults with AORC, this would be shortsighted since it relies on the vote-counting approach [35], an approach that has been shown to be less valid than the meta-analytic approach [35]. Recently, two members of the investigative team (GAK and KSK) conducted a systematic review of previous meta-analyses addressing the effects of exercise on depressive symptoms in adults with AORC [36]. Only two previous meta-analyses, limited to adults with fibromyalgia $[37,38]$, met the criteria for inclusion [36]. Exercise minus control group reductions in depressive symptoms were found for both meta-analyses (standardized mean difference (SMD), -0.61, 95\% confidence interval (CI), -0.99 to $-0.23, P=0.002$; SMD, -0.32 , $95 \% \mathrm{CI},-0.53$ to $-0.12, P=0.002$ [36]. Another metaanalysis that included participants with a variety of chronic illnesses and which was excluded from our previous review [36] found a SMD reduction of -0.29 (95\% CI, -0.16 to -0.43) in depressive symptoms among fibromyalgia participants as well as a reduction of -0.23 (95\% CI, -0.11 to -0.34) in participants with chronic pain other than fibromyalgia [39]. However, these latter findings included participants with conditions other than arthritis, for example back pain. In addition, while this previous meta-analysis included an analysis for such things as small-study effects, number-needed-to treat and metaregression, these analyses were conducted across all chronic illnesses versus those with AORC [39]. While these previous findings are encouraging, no metaanalysis focused specifically on the effects of exercise on depressive symptoms in adults with other AORC (osteoarthritis, rheumatoid arthritis, systemic lupus erythematous), met the eligibility criteria. Since the effects of exercise on depressive symptoms may vary across different AORC, the inclusion of such populations in a meta-analysis is important. In addition, the most recent meta-analysis of the two [38] was limited to studies published up until April 2009, suggesting the need for a more up-to-date review on the topic. Thus, the purpose of the current study was to conduct a systematic review with meta-analysis to determine the effects of exercise (aerobic, strength training, or both) on depressive symptoms in adults with AORC.

\section{Methods}

\section{Study eligibility criteria}

The a priori inclusion criteria for this meta-analysis were as follows: (1) randomized controlled trials with the unit of assignment at the participant level, (2) exercise-only intervention group (aerobic, strength training, or both), (3) community-deliverable exercise interventions $\geq 4$ weeks in duration, (4) comparative control group (non-intervention, usual care, wait-list control, attention control), (5) adults 18-years old and older with one of the following: rheumatoid arthritis, osteoarthritis, or fibromyalgia, (6) studies published in any language between 1 January 1981 and 1 January 2013, (7) depressive symptoms as an outcome. Post $h o c$, a decision was made to include studies in adults with systemic lupus erythematosus. For this proposed project, community-deliverable exercise interventions were defined as those that could be performed, or had the potential to be adapted and performed, by persons in a community setting (recreation or senior centers, in the home or neighborhood, etc.) and meet the implementation guidelines for physical activity interventions recommended by the Arthritis Program at the Centers for Disease Control and Prevention [40]. This includes exercise in a pool [40]. An exercise duration of at least four weeks was chosen based on previous meta-analytic research that included physical activity regimens of as little as four weeks and in which depressive symptoms were reduced in the general adult population [41]. Studies were limited to full articles published in peer-reviewed journals and examined for potential publication bias based on recent recommendations (see Statistical Analysis section for description) [42]. Unpublished work, defined as master's theses, dissertations, abstracts from conference proceedings, technical reports and studies filed in an investigator's drawer, was not included. The rationale for this decision was based on the work of van Driel et al. [43], who concluded that: (1) the difficulty in retrieving unpublished work could lead to selection bias, (2) many unpublished trials are eventually published, (3) the methodological quality of such studies is poorer than those that are published, and (4) the effort and resources required to obtain unpublished work may not be warranted [43]. This approach is consistent with recent practice [43]. The year 1981 was chosen as the starting point for study searches based on a preliminary search in PubMed in which the first cited randomized controlled trial on exercise and arthritis in adults was published in 1981 [44].

\section{Data sources}

Studies were retrieved using the following 10 electronic databases: (1) Medline, (2) CINAHL, (3) Sport Discus, (4) PsycINFO, (5) Scopus, (6) Academic Search Complete, (7) Proquest, (8) Cochrane Central Register of Controlled Trials, (9) PEDro and (10) Web of Science. All electronic searches were conducted by a Health Sciences librarian 
(JS) with assistance from the first and second authors. While the search strategies used varied according to the requirements of the different databases searched, keywords centered on the terms 'exercise', 'arthritis' and 'depression'. An example of the search strategy for one database (Scopus) can be found in Additional file 1. After removing duplicates and completing the study selection process, the overall precision of the searches was calculated by dividing the number of studies included by the total number of studies screened [45]. The number needed to read (NNR) was then calculated as the inverse of the precision [45]. In addition to electronic database searches, cross-referencing for potentially eligible meta-analyses from retrieved reviews was also conducted as well as expert review. All studies were stored in Reference Manager, version 12.0.1 [46].

\section{Study selection}

All studies were selected by the first two authors, independent of each other. Disagreements regarding the final list of studies to be included were resolved by consensus. Multiple publication bias was addressed by only including one set of data on the same subjects. All included studies, as well as a list of excluded studies, including reasons for exclusion, were stored in Reference Manager (version 12.0.1) [46].

\section{Data abstraction}

Prior to data abstraction, a detailed codebook that could hold up to 260 items per study was developed by all three members of the research team in Microsoft Excel 2007 [47]. The major categories of variables that were coded included: (1) study characteristics, (2) subject characteristics, (3) exercise program characteristics, (4) primary outcomes and (5) secondary outcomes. The primary outcome for this study, established a priori, was changes in depressive symptoms. Secondary outcomes included the following variables: body weight, body mass index (BMI) in $\mathrm{kg} \cdot \mathrm{m}^{2}$, percent body fat, physical function, pain (global), quality of life (overall score), anxiety, aerobic fitness $\left(\mathrm{VO}_{2 \max }\right.$ in $\left.\mathrm{ml} \mathrm{kg}^{-1} \mathrm{~min}^{-1}\right)$, muscular strength (upper and lower body) and balance (overall, dynamic or static). Secondary outcomes were only included if data for depressive symptoms were available. Our rationale for including these secondary outcomes was based on their potential impact on depressive symptoms as well as the fact that they are often at less than optimal levels in adults with AORC. All studies were coded by the first two authors, independent of each other. They then met and reviewed every entry $(22,136$ total) for accuracy and consistency. Discrepancies were resolved by consensus. If consensus could not be reached, the third author served as an arbitrator. Using Cohen's kappa statistic [48], the overall agreement rate prior to correcting discrepant items ranged from 0.70 to $0.98(\bar{x} \pm S D=0.89 \pm 0.07, \operatorname{Mdn}=0.90)$.

\section{Risk of bias}

The Cochrane Collaboration risk of bias instrument was used to assess bias across six domains: (1) random sequence generation, (2) allocation concealment, (3) blinding of participants and personnel, (4) blinding of outcome assessment, (5) incomplete outcome data, (6) selective reporting and (7) whether the participants were physically inactive, as defined by the original study authors, prior to taking part in the study [49]. Each item was classified as having a high, low, or unclear risk of bias [49]. Assessment for risk of bias was limited to the primary outcome of interest, changes in depressive symptoms. Since it is impossible to blind participants to group assignment in exercise intervention protocols, all studies were considered to be at a high risk of bias with respect to blinding of participants and personnel. Based on previous research, no study was excluded based on the results of the risk of bias assessment [50]. All assessments were performed by the first two authors, independent of each other. Both authors then met and reviewed every item (203 total) for agreement. Disagreements were resolved by consensus. Using Cohen's kappa statistic [48], the overall agreement rate prior to correcting discrepant items ranged from 0.14 to 0.71 $(\bar{x} \pm S D=0.63 \pm 0.32, \operatorname{Mdn}=0.71)$.

\section{Statistical analysis}

The $a$ priori plan was to conduct a one-step individual participant data (IPD) meta-analysis [51]. However, because of: (1) the inability to obtain IPD from all eligible studies, (2) the inability to resolve discrepancies between the IPD provided and data reported in the published studies, for example, final sample sizes and (3) the potential loss of power with fewer included studies at the IPD level, a post hoc decision was made to conduct an aggregate data meta-analysis, an approach similar to conducting a two-step meta-analysis with IPD [51].

\section{Calculation of effect sizes for primary and secondary outcomes from each study}

The primary outcome for this study was depressive symptoms, calculated as the SMD effect size $g$. This was accomplished by subtracting the change score difference in the exercise group from the change score difference in the control group. Variances were calculated from the pooled standard deviations of change scores in the intervention and control groups. If change score standard deviations were not available, these were calculated from reported 95\% CIs, pre and post standard deviation (SD) values according to procedures developed by Follmann et al. [52], or other traditional methods (for example, $t$ tests, exact probability values). Each $g$ was then weighted 
by the inverse of its variance and adjusted for small sample bias [53]. The beneficial effects of exercise on depressive symptoms were denoted by a negative $g$. Studies that used assessment instruments in which a positive $g$ represented reductions in depressive symptoms were reverse scaled so that negative values were indicative of improvements. In order to try to maintain independence as well as the fact that no one most valid and reliable measure for assessing depressive symptoms in adults with AORC exists, overall results were pooled for those studies that assessed depressive symptoms using more than one assessment instrument. The same approach was used for studies that reported results based on both intention-to-treat and per-protocol analyses. Effect sizes for secondary outcomes were calculated using either the original metric, for example body weight in kilograms, or $g$ given the different assessment instruments used for many of the included outcomes (anxiety, pain, and etc.). For all secondary outcomes the beneficial direction of effect reported was the natural direction of benefit, for example, negative values for decreases in anxiety, positive values for increases in quality-of-life. Where necessary, values were reverse-scaled. Similar to depressive symptoms, results were pooled for those studies that assessed any secondary outcomes using more than one assessment instrument and/or analyzed data using both the intention-to-treat and per-protocol approach.

\section{Pooled estimates for primary and secondary outcomes}

Random-effects, method-of-moments models that incorporate heterogeneity into the overall estimate were used to pool both primary and secondary outcomes from each study [54]. Multiple groups from the same study, for example aerobic and strength training groups, were analyzed independently as well as collapsing multiple groups so that only one result represented each outcome from each study. The rationale for collapsing multiple groups so that only one effect size represented each outcome from each study was based on the tendency for results from multiple groups in the same study to be correlated, the result being a loss of statistical independence. This study-level analysis was limited to overall findings only. All other analyses (influence analysis, cumulative meta-analysis, moderator analysis, simple meta-regression, etc.) were conducted with group level data. While results were pooled for those studies in which the same outcome was measured using more than one assessment instrument and/or results were reported using both intention-to-treat and per-protocol approaches, separate moderator analyses were also conducted for each assessment type and type of analysis. Non-overlapping 95\% CI were considered statistically significant. To enhance practical application, the number-needed-to treat (NNT) was calculated for any overall findings that were reported as statistically significant. This was accomplished using the approach suggested by the Cochrane Collaboration and assuming a control group risk of 30\% [55]. Briefly, based on recommendations of the Cochrane Collaboration [55], we converted the standardized mean difference into a natural log odds ratio, odds ratio, assumed control risk, based on $30 \%$, and finally, the NNT. The $30 \%$ control group risk was based on a previous review by Sonawalla and Rosenbaum [56] in which it was reported that mean placebo response rates in antidepressant clinical trials were $30 \%$ to $40 \%$. Based on the NNT for changes in depressive symptoms, gross estimates of the number of adults with AORC in the US who could benefit from exercise but were not meeting current exercise guidelines were calculated. This was based on an estimated 34.8 million US adults with doctordiagnosed arthritis, derived by multiplying the number of adults with doctor-diagnosed arthritis ( 55.2 million) [1] by the percentage of adults with arthritis who were not currently meeting physical activity guidelines (63\%) [5]. Practical application was further enhanced by calculating Cohen's $U_{3}$ index, an index used to determine the percentile gain in an intervention group [57]. For example, a g of 0.40 suggests that, on average, a person in the exercise group would be at approximately the 66th percentile in terms of improving their depressive symptoms. This translates into being approximately 16 percentiles higher than the control group [58].

\section{Stability and validity of changes in primary and secondary outcomes}

Heterogeneity of results between studies was examined using Q as well as an extension of the Q statistic, $I^{2}$ [59]. Statistical significance for $Q$ was set at an alpha value of $\leq 0.10$. For $I^{2}$, values of $<25 \%, 25 \%$ to $<50 \%, 50 \%$ to $<75 \%$ and $75 \%$ or greater were considered to represent very low, low, moderate and large amounts of inconsistency, respectively [59]. To determine treatment effects in a new trial, 95\% prediction intervals (PI) were also calculated $[60,61]$. Small-study effects (publication bias, and so on) were examined qualitatively and quantitatively based on recent recommendations [42]. This included funnel plots as well as the regression approach of Egger et al. [42,62]. Non-overlapping 95\% CIs for Egger's regression test for the intercept $\left(\beta_{0}\right)$ were considered to be indicative of small-study effects. Outliers were considered to be individual study results in which their 95\% CI did not overlap with the 95\% CI from pooled results. In order to examine the effects of each result from each study on the overall findings, results were analyzed with each study deleted from the model once. Cumulative meta-analysis, ranked by year, was used to examine the accumulation of evidence over time [63]. Cumulative metaanalysis is an approach where studies are added one at a time and the results summarized as each new study is 
added. This allows one to visually examine how results have accumulated, and possibly changed, over time [63].

\section{Moderator analysis for depressive symptoms}

Within and between-group differences in depressive symptoms for categorical variables were examined using mixed effects models that consisted of a random-effects model for combining studies within each subgroup and a fixed effect-model across subgroups [64]. Betweenstudy variance (tau-squared) was considered to be unequal for all subgroups. This value was computed within subgroups but not pooled across subgroups. Categorical analyses included: (1) study characteristics (country, type of control group, whether IPD was provided, random sequence generation, allocation concealment, blinding of participants and personnel, blinding of outcome assessor, incomplete data, selective outcome reporting, whether subjects were physically inactive prior to enrollment as defined by the original study authors, type of analysis performed, provision of sample-size estimates, whether the study was funded, method to assess depression), (2) participant characteristics (adverse events, sex, race/ethnicity, cigarette smoking, whether participants were overweight and/or obese (BMI $\geq 25 \mathrm{~kg} / \mathrm{m}^{2}$ ), type of AORC, medications taken for AORC) and (3) exercise intervention characteristics (type, intensity, delivery). Intensity for aerobic exercise was categorized as low $(<40 \%$ of heart rate $/ \mathrm{VO}_{2}$ reserve or $<55 \%$ of maximal heart rate), moderate (between $40 \%$ and $59 \%$ of heart rate/ $\mathrm{VO}_{2}$ reserve or $55 \%$ and $69 \%$ of maximal heart rate) or high ( $>59 \%$ of heart rate $/ \mathrm{VO}_{2}$ reserve or $>69 \%$ of maximal heart rate) [65]. Intensity for strengthening exercise was categorized as low ( $<50 \%$ of 1 -repetition maximum), moderate (between $50 \%$ and $69 \%$ of 1-repetition maximum) or high ( $>69 \%$ of 1-repetition maximum for strength exercise) [65]. Post hoc, type of exercise was also examined by separating out tai chi and qi gong from combined aerobic and strength training. The rationale for this was based on the fact that both tai chi and qi gong are considered to be meditative movement therapies which include a mental component that is not traditionally included in typical aerobic and strength training interventions. Non-overlapping 95\% CI for both within and between-group analyses were considered statistically significant. All moderator analyses were considered exploratory [66].

\section{Meta-regression for changes in depressive symptoms and potential covariates}

Simple mixed-effects, method of moments meta-regression was used to examine the potential association between changes in depressive symptoms and continuous variables [64]. Because missing data for different variables from different studies was expected, only simple meta-regression was planned and performed. Potential predictor variables included: (1) study characteristics (year of publication, percentage of dropouts), (2) participant characteristics (age, symptom duration, diagnosis duration, changes in body weight, BMI in $\mathrm{kgm}^{2}$, percent body fat, physical function, pain, quality of life, anxiety, maximum oxygen consumption, expressed as $\mathrm{VO}_{2 \max }$ in $\mathrm{mlkg}^{-1} \cdot \mathrm{min}^{-1}$, upper and lower body strength, balance) and (3) exercise intervention characteristics (length, frequency, duration of training, compliance, total minutes per week, calculated as frequency $\mathrm{x}$ duration, total minutes per week, adjusted for percent compliance, total minutes of training for the entire intervention period, calculated as length $\mathrm{x}$ frequency $\mathrm{x}$ duration, and total minutes of training, adjusted for compliance). Nonoverlapping $95 \% \mathrm{CI}$ for the slope $\left(\beta_{1}\right)$ were considered statistically significant. Because this was a meta-analysis, all meta-regression analyses were considered exploratory [66].

\section{Software used for statistical analysis}

Analyses were carried out using Comprehensive MetaAnalysis (version 2.2) [67], Microsoft Excel 2010 [68], and two external add-ins for Excel, SSC-Stat (version 2.18) [69] and EZ-Analyze (version 3.0) [70].

\section{Reporting metrics}

Selected data are reported as mean \pm standard deviation $(\bar{x} \pm S D)$ and median (Mdn).

\section{Results}

\section{Study characteristics}

A general description of the characteristics of each study is shown in Table 1 . Of the 500 citations reviewed, a total of 2,449 participants (1,470 exercise, 979 control) nested within 64 groups (35 exercise, 29 control) and 29 studies were included in the final analysis [6-34]. The precision of the searches was 0.06 while the NNR was 17. A description of the search process, including the reasons for excluded studies, is shown in Figure 1 while a list of each excluded study, including the reason(s) for exclusion, is shown in Additional file 2. The number of exercise groups exceeded the number of studies because six studies included more than one group $[11,19,20,23,24,26]$. The number of subjects in each group from each study varied widely, ranging from 8 to 149 in the exercise groups $(\bar{x} \pm S D=42 \pm 35, \mathrm{Mdn}=28)$ and 8 to 144 in the control groups $(\bar{x} \pm S D=34 \pm 30, \mathrm{Mdn}=27)$. Twenty-eight studies were published in English language journals [6-27,29-34] and one in Spanish [28]. Studies were conducted in eleven different countries; thirteen in the United States [7-10,16,17,19,20,22-24,32,33], two each in either Brazil [15,30], Canada [12,26], Finland [14,31], Portugal $[28,29]$, Spain $[6,25]$ or Sweden $[13,18]$, and one each in either Australia [11], Norway [34], Turkey [27], or the United Kingdom [21]. For types of controls, eight 


\section{Table 1 General characteristics of studies}

\section{Study \\ Participants}

Alentorn-Geli et al [6] Spain

24 women with FM randomly assigned to either an exercise

$(n=12, \bar{x} \pm S D=53.7 \pm 9.4$ yrs) or control group

$(\mathrm{n}=12$, age, $\bar{x} \pm \mathrm{SD}=59.3 \pm 7.3 \mathrm{yrs})$

Buckelew et al. [7] United States

60 men and women with FM assigned to either an exercise $(n=30$, age $\bar{x} \pm S D=45.6 \pm 9.4$ yrs $)$ or attention control group $(n=30$, age, $\bar{x} \pm S D=44.3 \pm 11.2 \mathrm{yrs})$

Daltroy et al. [8] United States

71 men and women with either RA or SLE assigned to either an exercise $(n=35$, age $\bar{x} \pm S D=38.4 \pm 7.5$ yrs, range $18-50$ yrs $)$ or an attention control group ( $n=36$, age, $\bar{x} \pm S D=35.7 \pm 7.1$ yrs, range $18-50 \mathrm{yrs}$ )

Etnier et al., [9] United States 16 women (age $\bar{x} \pm \mathrm{SD}=55.1 \pm 8.9 \mathrm{yrs}$, range $32-70 \mathrm{yrs}$ ) with FM assigned to an exercise $(n=8)$ or wait-list control group $(n=8)$

Fontaine et al., [10] United States 84 men and women with FM assigned to a lifestyle physical activity ( $n=46$, age, $\bar{x} \pm S D=46.4 \pm 11.6$ yrs) or control group ( $n=38$, age, $\bar{x} \pm S D=49 \pm 10.2 \mathrm{yrs}$ )

Fransen et al., [11] Australia $\quad 152$ men and women with OA of the hip or knee assigned to a hydrotherapy $(n=55$, age, $\bar{x} \pm S D=70 \pm 6.3 \mathrm{yrs})$, to a hydrotherapy ( $n=55$, age, $x \pm S D=70 \pm 6.3 \mathrm{yrs}$ ),
tai chi $(n=56, \bar{x} \pm S D=70.8 \pm 6.3 \mathrm{yrs})$, or control group $(\mathrm{n}=41$, age, $\bar{x} \pm \mathrm{SD}=69.6 \pm 6.1 \mathrm{yrs})$

Gowans et al., [12] Canada

57 men and women with FM assigned to an exercise $(n=30$ age, $\bar{x} \pm \mathrm{SD}=44.6 \pm 8.7 \mathrm{yrs}$ ), or control group $(\mathrm{n}=27$, age, $\bar{x} \pm \mathrm{SD}=49.8 \pm 7.3 \mathrm{yrs})$

Haak and Scott, [13] Sweden 57 women with FM assigned to an intervention $(\mathrm{n}=29, \bar{x} \pm \mathrm{SD}=54 \pm 9.4$ yrs of age) or wait-list control group ( $n=28, \bar{x} \pm S D=53.4 \pm 8$ yrs of age)

Hakkinen et al [14] Finland

21 premenopausal women with FM assigned to a progressive strength training $(n=11, \bar{x} \pm S D=39 \pm 6$ yrs $)$ or control group $(n=10, \bar{x} \pm S D=37 \pm 5$ yrs $)$

Ide et al., [15] Brazil

Jones et al., [16] United States

40 women with FM assigned to either an exercise ( $n=20$, age, $\bar{x} \pm S D=46.6 \pm 9.8$ yrs) or control group $(\mathrm{n}=20$, age, $\bar{x} \pm \mathrm{SD}=45.5 \pm 8.65 \mathrm{yrs})$

101 men and women with FM assigned to a placebo and exercise $(n=47, \bar{x} \pm S D=49.6 \pm 7.7$ yrs of age) or attention control: placebo plus diet recall group $(n=54, \bar{x} \pm S D=49.8 \pm 7.9$ yrs of age)

Komatireddy et al, [17] United States

49 men and women with RA assigned to a circuit training $(n=25, \bar{x} \pm S D=57.7 \pm 9.8$ yrs of age, range $40-72 \mathrm{yrs})$ or control group $(n=24, \bar{x} \pm S D=60.5 \pm 11$ yrs of age, range $35-76$ yrs)

Mannerkorpi et al., [18] Sweden 69 women with FM assigned to either a training

\section{Exercise intervention}

$2 \times / w k, 90 \mathrm{~min} / \mathrm{d}$ (aerobic, $30 \mathrm{~min}$ walking, 65-85\%

MHR, or salsa dancing: 2, 15/min sessions plus

stretching and relaxation exercises) for 6 wks

1-3 x/wk, 1.5-3 hr/session, ROM exercises, strengthening exercises, and low-moderate intensity aerobic exercise (walking at 60-70\% MHR) for 6 wks

22 x/wk, 30 min/session, home-based, unsupervised

aerobic exercise (walk, jog, cycle, swim) at

60-80\% MHR for 24 wks

$3 \mathrm{~d} / \mathrm{wk}, 60 \mathrm{~min} / \mathrm{session}$ : walk, $15 \mathrm{~min}, 55-65 \%$ MHR, 8-station light resistance exercise circuit, static-bridging exercises, stretching, for $18 \mathrm{wks}$

5-7 d/wk, accumulate 30 min of moderate-intensity physical activity in short bouts throughout the day by walking, garden/outdoor, household or sports activity for 12 wks

$2 \times / w k, 1$ hr/session, of either Tai Chi (for Arthritis,

24 modified forms of Sun style) or hydrotherapy

exercises in warm water, for 12 wks

$3 \mathrm{~d} / \mathrm{wk}, 30 \mathrm{~min} / \mathrm{session}$, aerobic exercise (2 walking/jogging classes in a gym, 1 pool class) at 60-75\%MHR, for 23 wks

qigong, 9 group sessions over 7 weeks (11.5 hours total), $2 \times$ per day at home for 20 minutes each

2 days/wk of supervised progressive strength training 6-8 exercises, 8-20 reps, 40-80\% 1RM, for 21 weeks

$4 \mathrm{~d} / \mathrm{wk}, 1 \mathrm{hr} /$ session, aquatic respiratory exercise-based program in warm water, for 4 wks

3 x/wk, $60 \mathrm{~min} /$ session, low-impact, nonrepetitive cardioaerobics (30 min), strength training $(10 \mathrm{~min})$, flexibility training $(5 \mathrm{~min})$, balance training $(5 \mathrm{~min})$, and relaxation (10 min) at 40-50\% MHR or Borg RPE and relaxation (10 $\mathrm{min})$ at $10-12$, for 6 months

Circuit weight bearing with light loads and high repetitions, 7 exercises, 2-3 circuits/session, 12-15 reps,30-second rest between sets, 20-27 min/session, at least $3 \times / w k$, RPE of $3-4$, for 12 wks

$1 \mathrm{~d} / \mathrm{wk}, 35 \mathrm{~min} / \mathrm{session}$, endurance, flexibility, coordination $(n=37, \bar{x} \pm S D=45 \pm 8$ yrs of age) or control group $(n=32, \bar{x} \pm S D=47 \pm 11.6$ yrs of age $)$

\section{Depression assessment}

FIQ (depression)

DASS-21

$\mathrm{BDI}, \mathrm{MHI}$ (depression)

FIQ (depression)

FIQ (depression)

AIMS (depression)

FIQ (depression), AIMS (depression) 
Table 1 General characteristics of studies (Continued) \begin{tabular}{lll}
\hline Minor et al., [19] United States & 115 men and women ages 21-83 yrs with RA \\
& $\begin{array}{l}\text { or OA assigned to a pool }(n=47), \text { walking } \\
(n=36) \text { or control group }(n=32)\end{array}$
\end{tabular}

Neuberger et al., [20] United States 310 men and women age 55.5, range 40-70 yrs, with RA assigned to a class $(n=102)$, or home-based (videotape) exercise $(n=103)$, or control group $(n=105)$

O'Reilly et al., [21] United Kingdom 191 men and women with knee OA ages 40-80 yrs yrs of age) or control group ( $n=78, \bar{x} \pm S D=62.2$ yrs of age)

Patrick et al., [22] United States 249 men and women 55-75 yrs of age with OA assigned to either an exercise $(n=125,65.7 \mathrm{yrs}$ of age) or wait-list control group ( $n=124,66.1$ yrs of age)

Penninx et al., [23] United States 439 men and women $(\bar{x} \pm \mathrm{SD}=68.8 \pm 5.6 \mathrm{yrs}$ of age $)$ assigned to an aerobic $(n=149)$, resistance, $(n=146)$ or control group $(n=144)$

Rooks et al., [24] United States 152 women with FM assigned to an aerobic and flexibility ( $n=51, \bar{x} \pm S D=48 \pm 11$ yrs of age), strength training, aerobic, and flexibility $(n=51, \bar{x} \pm S D=50 \pm 11$ yrs of age) or control group $(n=50, \bar{x} \pm S D=51 \pm 12$ yrs of age)

Sanudo et al., [25] Spain $\quad 42$ women with FM assigned to an exercise $(\mathrm{n}=21, \bar{x} \pm S D=55.5 \pm 7.1 \mathrm{yrs}$ of age) or control group $(n=21, \bar{x} \pm S D=56.2 \pm 8.5$ yrs of age)

Schachter et al., [26] Canada

143 women with FM (20-55 yrs of age) assigned to a short bout ( $n=56, \bar{x} \pm S D=41.9 \pm 8.6$ yrs of age), long bout $(n=51, \bar{x} \pm S D=41.3 \pm 8.7$ yrs of age), or control group $(n=36, \bar{x} \pm S D=42.5 \pm 6.7$ yrs of age)

Sencan et al. [27] Turkey

Tomas-Carus et al. [28] Portugal

Tomas-Carus et al. [29] Portugal

Valim et al. [30] Brazil

40 women with FM assigned to an aerobic exercise $(\mathrm{n}=20, \bar{x} \pm S D=35.4 \pm 9.6$ yrs of age) or control TENS treatment group $(n=20, \bar{x} \pm S D=35.55 \pm$ 7.9 yrs of age)

34 women with $\mathrm{FM}$ assigned to aquatic exercise $(n=17, \bar{x} \pm S D=51 \pm 10$ yrs of age) or control group ( $n=17, \bar{x} \pm S D=51 \pm 9$ yrs of age)

33 women with FM assigned to aquatic exercise $(n=17, \bar{x} \pm S D=50.7 \pm 10.6$ yrs of age) or contro group $(n=16, \bar{x} \pm S D=50.9 \pm 6.7 \mathrm{yrs}$ of age $)$

76 women with $\mathrm{FM}$ assigned to an exercise $(n=38, \bar{x} \pm S D=47 \pm 10$ yrs of age) or stretching group $(n=38, \bar{x} \pm S D=44 \pm 11$ yrs of age)

$3 \times /$ wk, $1 \mathrm{hr} /$ session (30 min of this was aerobic), $60-80 \%$ MHR, for 12 wks either in a pool (aerobic

aquatics) or walk (aerobic walking) group

$3 \mathrm{~d} / \mathrm{wk}, 1 \mathrm{hr} / \mathrm{session}$, low-impact aerobics (25.4 min range 10-30 $\mathrm{min} / \mathrm{session}$ ) and strength training

(16.67 $\mathrm{min}$, range $15-20 \mathrm{~min} / \mathrm{session}$ ), 60-80\%

MHR, for 12 wks

5 strengthening exercises, 20 reps per leg, performed

at home on a daily basis for 6 months

2-7 d/wk, 45-60 min/session of aquatic exercise, for 20 wks

78 wks of training; Aerobic group: $3 \mathrm{~d} / \mathrm{wk}, 40 \mathrm{~min} / \mathrm{session}$ 50-70\%HRR, walking; Resistance group: $3 \mathrm{~d} / \mathrm{wk}, 40 \mathrm{~min} / \mathrm{session}$ 2 sets, 10 reps using dumbbells and cuff weights

$3 \mathrm{~d} / \mathrm{wk}$, of either aerobic (45 min walking) and flexibility exercises or aerobic (20 min walking), strength training (25 min, 6 exercises, 50\% 1RM, 1-2 sets of $6-12$ reps) and flexibility exercises for 16 wks

$2 \times /$ wk, aerobic (walk/jog, 10-15 min, 65-70\% MHR) strength training (15-20 min, circuit of 8 exercises, 1 set, $8-10$ reps), and flexibility exercises $(10 \mathrm{~min}$ 8-9 stations, 1 set, 3 reps for $30 \mathrm{sec})$, for 24 wks

Home-based, videotape-based, low impact aerobic exercise to music. Short bout group: 2 x/d, 7.1 x/wk $12.3 \mathrm{~min} / \mathrm{session,} 60 \%$ HRR; Long-bout group: $1 \mathrm{x} / \mathrm{d}$, 3.6 x/wk, $25.5 \mathrm{~min} / \mathrm{session}, 60 \%$ HRR, for 16 wks

$3 \times /$ wk, $40 \mathrm{~min} / \mathrm{session}$, aerobic exercise (cycle ergometer for $30 \mathrm{~min}$, plus $5 \mathrm{~min}$ warm-up and $5 \mathrm{~min}$ cool-down) for 6 wks

$3 x /$ wk, pool exercises performed in warm water, $20 \mathrm{~min}$ aerobic, 60-65\% MHR, 20 min strength exercises, 4 sets, 10 reps, for 12 wks

$3 x / w k$, pool exercises performed in warm water, $20 \mathrm{~min}$ aerobic, 60-65\% MHR, 20 min strength exercises, 4 sets, 10 reps, for 8 months

$3 \mathrm{x} / \mathrm{wk}$, $45 \mathrm{~min} / \mathrm{session}$, aerobic exercise group walked, for 20 wks. Stretching (control) group $3 \times / w k, 45$ min/session, 17 exercises for flexibility but without raising $H R$, for 20 wks
AIMS (depression)

CES-D, POMS

FIQ (depression), BDI

FIQ (depression)

\section{FIQ (depression)}

FIQ (depression) 
Table 1 General characteristics of studies (Continued)

\begin{tabular}{|c|c|c|c|c|}
\hline Valkeinen et al. [31] & Finland & $\begin{array}{l}26 \text { women with FM assigned to a strength training } \\
\text { ( } n=13, \bar{x} \pm S D=60.2 \pm 2.5 \text { yrs of age, range } 57-64 \text { yrs }) \\
\text { or control group }(n=13, \bar{x} \pm S D=59.1 \pm 3.5 \text { yrs of age, } \\
\text { range } 54-65 \text { yrs })\end{array}$ & $\begin{array}{l}2 \times / \text { wk, } 60-90 \mathrm{~min} / \text { session, strength training, } 7-8 \\
\text { exercises, 3-5 sets, 5-20 reps, 40-70\% } 1 \text { RM, for } \\
21 \text { wks }\end{array}$ & $\mathrm{BDI}$ \\
\hline Wang et al. [32] & United States & $\begin{array}{l}40 \text { men and women with knee } O A \text { assigned to a Tai Chi } \\
\text { ( } n=20, \bar{x} \pm S D=63 \pm 8.1 \text { yrs of age) or attention control } \\
\text { group }(n=20, \bar{x} \pm S D=68 \pm 7 \text { yrs of age) }\end{array}$ & $\begin{array}{l}2 \mathrm{~d} \text { of supervised Tai Chi for } 30 \mathrm{~min} \text {; Tai Chi every } \\
\text { day at home for at least } 20 \text { min; } 10 \text { forms of } \\
\text { classic Yang style Tai Chi, for } 12 \text { wks }\end{array}$ & CES-D \\
\hline Wang et al. [33] & United States & $\begin{array}{l}66 \text { men and women with FM assigned to a Tai Chi } \\
\text { ( } n=33, \bar{x} \pm S D=49.7 \pm 11.8 \text { yrs of age) or attention } \\
\text { control group }(n=33, \bar{x} \pm S D=50.5 \pm 10.5 \text { yrs of age) }\end{array}$ & $\begin{array}{l}2 \mathrm{~d} \text { of supervised Tai Chi (Yang Style-10 forms) } \\
\text { for } 60 \mathrm{~min} \text {; Tai Chi every day at home for at } \\
\text { least } 20 \mathrm{~min} \text {, for } 12 \text { wks }\end{array}$ & CES-D \\
\hline Wigers et al. [34] & Norway & $\begin{array}{l}40 \text { men and women with } F M \text { assigned to an aerobic } \\
\text { exercise ( } n=20, \bar{x} \pm S D=43 \pm 9 \text { yrs of age, range } 23-62 \mathrm{yrs}) \\
\text { or treatment-as-usual group ( } n=20, \bar{x} \pm S D=46 \pm 9 \mathrm{yrs} \\
\text { of age, range } 29-73 \text { yrs) }\end{array}$ & $\begin{array}{l}3 \times / \mathrm{wk}, 18-20 \mathrm{~min} / \mathrm{session} \text { of aerobic exercise with } \\
\text { 1) music session, 2) aerobic games (tag, ball games) } \\
\text { at } 60-70 \% \text { MHR, for } 14 \text { wks }\end{array}$ & VAS \\
\hline
\end{tabular}

wk, week(s); $x$, times; $\bar{x} \pm \mathrm{SD}$; mean \pm standard deviation; $y r$, year(s). 


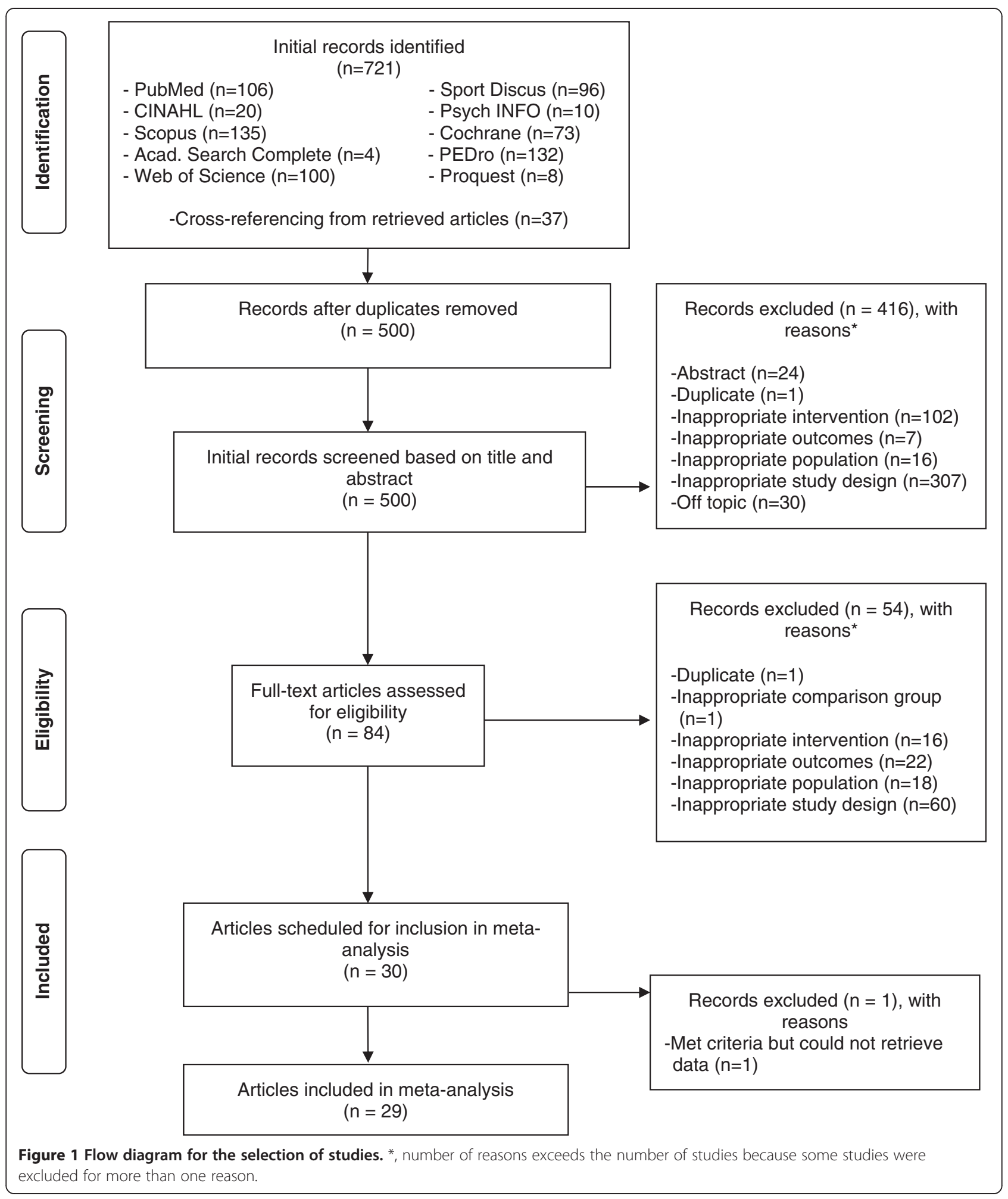

appeared to use a non-intervention control group $[6,12,14,17,20,21,29,31]$, six used an attention control group $[7,8,10,16,32,33]$, four used a wait-list control $[9,11,13,22]$, three used usual care [25,28,34], and eight were control groups which could not be definitively categorized $[15,18,19,23,24,26,27,30]$. Prior to randomization, nine studies matched participants according to either sex [12,20,22], age and sex [21], age, sex and BMI [16], age and duration 
of symptoms [18], disease status [8], diagnosis of rheumatoid arthritis or osteoarthritis [19], or score on the Fibromyalgia Impact Questionnaire [24]. None of the studies used a crossover design. For data analysis, 19 studies reported using the per-protocol approach only [6-10,13-22,27-30], five used the intention-to-treat approach $[11,23,25,32,33]$ and four used both $[12,24,26,34]$. One other study essentially used an intention-to-treat approach because they reported no dropouts [31]. Sample size justification was provided by $14(48.3 \%)$ of the studies $[8,10,11,16,20-22,24-26,28,30,32,33]$ while 23 (79.3\%) reported receiving some type of funding to conduct their investigation [7-12,14,16-24,26,29-34]. Only seven studies (24.1\%) provided IPD [7,9,11,20,26,27,31]. Dropout data, available for 32 (91.4\%) of the exercise groups ranged from $0 \%$ to $50 \%(\bar{x} \pm \mathrm{SD}=16.2 \% \pm 12.2 \%, \mathrm{Mdn}=15.3 \%)$ while control group dropouts ranged from $0 \%$ to $46 \%(\bar{x} \pm \mathrm{SD}=$ $14.1 \% \pm 13.3 \%, \mathrm{Mdn}=12.5 \%)$ for the $25(86.2 \%)$ groups in which data were available. Reasons for participants dropping out or for the investigative team to drop participants from their study included the following: (1) personal reasons, for example, family or job issues, moved, (2) travel issues, (3) schedule conflicts, (4) health issues, (5) time, (6) not attending the requisite number of exercise sessions, (7) lost to follow-up, (8) began taking medications not allowed during the intervention, (9) pain when exercising, (10) began other exercise, (11) identification of a comorbidity during the intervention, (12) unhappy or unwilling to accept group assignment, (13) exercise too time consuming or boring, (14) increased pain, (15) not enough room or privacy to perform exercises, (16) drug intolerance, (17) incomplete assessments, (18) lost contact with participant, (19) initiated additional treatments and (20) changed medications.

\section{Participant characteristics}

A description of the participant characteristics is shown in Tables 1 and 2. The majority of participants were women; fourteen studies were limited to women [6,9,13-15,18,24-31] while fifteen included both men and women $[7,8,10-12,16,17,19-23,32-34]$. No study was limited to men. With respect to race/ethnicity and as reported by the original study authors, the majority of participants were non-Hispanic Whites for the fifteen studies in which data were reported $[6,8,10,15,16,19,20,22-26,31-33]$. Twelve of the fifteen studies included multiple races/ethnicities $[8,10,15,16,19,20,22-24,26,32,33]$. The other three studies were limited to non-Hispanic Whites [31] or other Hispanics [6,25]. Groups represented in the studies included Whites, African-Americans, Hispanics, NativeAmericans and Aboriginals. Two studies reported that some of the participants smoked cigarettes $[8,26]$ while one reported that some participants consumed alcohol [8]. Another two studies reported that exercise participants increased their exercise outside the actual intervention $[10,25]$. With respect to cardiovascular disease risk factors, one study was limited to overweight and obese participants [25] while twelve others included some participants who were overweight or obese $[6,10,11,14,16,23,24,29-33]$. Two studies reported that none of the exercise or control group participants had type 1 or type 2 diabetes [12,27], while one reported that none of the exercise group participants had type 2 diabetes [32]. Two studies reported that none of the participants were hypertensive $[12,16]$ while six included some who were hypertensive $[6,9,19,23,32,33]$.

For type of AORC, 20 of 29 studies (69.0\%) were limited to participants with fibromyalgia $[6,7,9,10,12-16,18,24-31$, $33,34]$, five with osteoarthritis [11,21-23,32], and two with rheumatoid arthritis $[17,20]$. One study included participants with either rheumatoid arthritis or systemic lupus erythematosus [8] while another included participants with osteoarthritis or rheumatoid arthritis [19]. For the 14 exercise $(40 \%)$ and 13 control (44.8\%) groups in which sufficient data were provided, the number of years in which rheumatic symptoms were present ranged from 4.7 to 24.0 years in the exercisers $(\bar{x} \pm \mathrm{SD}=$ $12.2 \pm 5.2, \mathrm{Mdn}=10.7)$ and 5.1 to 19.4 years in the controls $(\bar{x} \pm \mathrm{SD}=11.7 \pm 4.2, \mathrm{Mdn}=10.0)$. With respect to years since diagnosis, exercise groups ranged from 2.8 to 9.8 years $(\bar{x} \pm \mathrm{SD}=5.5 \pm 2.5, \mathrm{Mdn}=5.5)$ for the ten

Table 2 Initial physical characteristics of participants

\begin{tabular}{|c|c|c|c|c|c|c|c|c|}
\hline \multirow[b]{2}{*}{ Variable } & \multicolumn{5}{|l|}{ Exercise } & \multicolumn{3}{|l|}{ Control } \\
\hline & Groups (Number) & $\bar{x} \pm S D$ & Mdn & Range & Groups (Number) & $\overline{\bar{x} \pm \mathrm{SD}}$ & Mdn & Range \\
\hline Age (yrs) & 33 & $52.4 \pm 9.7$ & 51 & $35-71$ & 28 & $52.2 \pm 9.6$ & 51 & $36-70$ \\
\hline Height (cm) & 7 & $160.3 \pm 2.9$ & 161 & $157-165$ & 6 & $160.9 \pm 2.0$ & 161 & $158-164$ \\
\hline Body weight (kg) & 9 & $70.1 \pm 4.9$ & 69 & $63-77$ & 8 & $71.4 \pm 4.0$ & 72 & $64-76$ \\
\hline BMI $\left(\mathrm{kg} \mathrm{m}^{2}\right)$ & 15 & $28.8 \pm 2.5$ & 29 & $24-34$ & 13 & $28.6 \pm 2.9$ & 29 & $25-32$ \\
\hline Body fat (\%) & 3 & $34.9 \pm 0.8$ & 35 & $34-35$ & 3 & $35.1 \pm 2.9$ & 36 & $32-38$ \\
\hline Symptom duration (yrs) & 14 & $12.2 \pm 5.2$ & 11 & $5-24$ & 13 & $11.7 \pm 4.2$ & 10 & $5-19$ \\
\hline Diagnosis (yrs) & 10 & $5.5 \pm 2.5$ & 5 & $3-10$ & 8 & $6.2 \pm 2.8$ & 6 & $3-11$ \\
\hline
\end{tabular}

Groups, number of groups in which data were available. BMI, body mass index; Mdn, median; $\bar{x} \pm S D$, mean \pm standard deviation; yrs, years. 
(28.6\%) groups in which data were available while the control groups ranged from 2.5 to 10.5 years $(\bar{x} \pm \mathrm{SD}=6.2 \pm$ $2.8, \mathrm{Mdn}=6.3)$ for the eight $(27.6 \%)$ groups in which data were provided.

\section{Exercise intervention characteristics}

A description of the exercise interventions for each included study is shown in Table 1. As can be seen, the exercise interventions varied considerably. Length of training ranged from 4 to 78 weeks $(\bar{x} \pm \mathrm{SD}=19 \pm 16$, $\mathrm{Mdn}=16$ ), frequency (34 groups reporting) from 1 to 9 times per week ( $\bar{x} \pm \mathrm{SD}=4 \pm 2, \mathrm{Mdn}=3)$ and duration (31 groups reporting) from 12 to 83 minutes per session $(\bar{x} \pm \mathrm{SD}=34 \pm 17, \mathrm{Mdn}=30)$. For the eighteen groups $(51.4 \%)$ in which data were provided, intensity of training was classified as low for three groups, moderate for eleven and high for four. Fifteen of the groups focused on aerobic exercise, five on strength training and eleven on both. Another four groups participated in meditative movement therapies that included either tai chi (three groups) or qigong (one group). Meditative movement therapies were considered as including both aerobic and strength training components. With respect to supervision, eighteen groups participated in supervised exercise, seven in unsupervised exercise and ten in both. The setting in which the groups exercised mirrored supervision, with eighteen taking place in a facility-based environment, seven in a home-based environment, and ten in both. For the 20 groups (57.1\%) in which data were available, compliance, defined as the percentage of exercise sessions attended, ranged from $38 \%$ to $97 \%(\bar{x} \pm \mathrm{SD}=$ $74 \pm 13, \mathrm{Mdn}=75$ ). Total minutes per week of exercise for the 30 groups $(85.7 \%)$ in which data could be calculated, ranged from 30 to $360(\bar{x} \pm \mathrm{SD}=108 \pm 67, \mathrm{Mdn}=$ 90 ). When adjusted for compliance (20 groups or $57.1 \%$ of all groups) total minutes per week ranged from 25 to $277(\bar{x} \pm \mathrm{SD}=72 \pm 60, \mathrm{Mdn}=57)$. Total minutes of training over the entire length of the interventions (30 groups) ranged from 360 to $9,360(\bar{x} \pm \mathrm{SD}=2,080 \pm$ $2,186, \mathrm{Mdn}=1,404)$. When adjusted for compliance (20 groups) total minutes ranged from 331 to 5,887 ( $\bar{x} \pm$ $\mathrm{SD}=1,532 \pm 1,609, \mathrm{Mdn}=839$ ).

\section{Risk of bias assessment}

Risk of bias results are shown in Figure 2 while results for each item from each study are shown in Additional file 3. Twenty-eight of twenty-nine studies [6-25,27-34] were considered to be at low risk with respect to sequence generation while one was considered to be at high risk [26]. Allocation concealment was poorly reported; seven studies were considered to be at low risk [15,21,24,25,29,32,33], one at high risk [26] and the remaining twenty-one at unclear risk [6-14,16-20,22,23,27,28,30,31,34]. Since it is impossible to blind participants in exercise intervention studies, all included trials were considered to be at a high risk of bias for the blinding of participants and personnel category [6-34]. Blinding of outcome assessment was also poorly reported, with ten studies considered being at low risk $[6,11,12,15,17,20,24,25,29,30]$, one at high risk [21], and eighteen at unclear risk [7-10,13,14,16,18,19,22,23, 26-28,31-34]. For incomplete data, that is, attrition bias, nineteen studies were considered to be at low risk for bias $[6,7,10-13,15-18,22,23,25,26,29,31-34]$, two at high risk $[20,30]$ and eight at unclear risk $[8,9,14,19,21,24,27,28]$. For selective outcome reporting, twenty-five studies were considered to be at an unclear risk [6-10,12-23,25-31,34] while four were considered low risk $[11,24,32,33]$. With regard to participants not exercising regularly prior to enrollment, thirteen studies were considered to be at low risk [7,9-11,16,19,20,22,23,26,28-30], one at high risk [8], and the remaining fifteen at unclear risk $[6,12-15,17,18,21,24,25,27,31-34]$.

\section{Primary outcome \\ Depressive symptoms}

Overall, there was a statistically significant reduction in depressive symptoms as well as a statistically significant and moderate amount of heterogeneity (Table 3 and Figure 3). In addition, 95\% PIs were non-significant. Statistically significant small-study effects were observed as indicated by funnel plot asymmetry (Figure 4) as well as overlapping $95 \% \mathrm{CI}$ based on Egger's regression intercept test $\left(\beta_{0},-2.4,95 \% \mathrm{CI},-3.7\right.$ to -1.1$)$ [62]. Reductions in depressive symptoms remained statistically significant when data were collapsed so that only one g represented each study $(\bar{x},-0.48,95 \% \mathrm{CI},-0.67$ to $-0.30 ; \mathrm{Q}=164.4$, $\left.P<0.001 ; I^{2}=83.0 \%\right)$. When four outliers were deleted from the model $[16,20,27,31]$, results remained statistically significant $(\bar{x},-0.44,95 \% \mathrm{CI},-0.58$ to $-0.31 ; \mathrm{Q}=$ 73.8, $\left.P<0.001 ; I^{2}=59.4 \%\right)$. With each group deleted from the model once, results remained statistically significant across all deletions (Figure 5). The difference between the largest and smallest values with each group deleted was 0.05 (11.8\%). Cumulative meta-analysis, ranked by year, demonstrated that results have been statistically significant since the first included study was published in 1989 (Figure 6) [19]. The NNT was 7 (95\% CI, 6 to 11) with an estimated 3.1 million (95\% CI, 2.0 to 3.7) US adults not currently meeting physical activity guidelines improving their depressive symptoms if they began and maintained a regular exercise program. Using Cohen's $\mathrm{U}_{3}$ Index, the percentile reduction was $16.4 \%$ ( $95 \%$ CI, $10.4 \%$ to $21.9 \%$ ).

Exploratory moderator (categorical) analyses for changes in depressive symptoms are shown in Additional file 4. As can be seen, statistically significant within-group reductions in depressive symptoms were observed for the majority of analyses. However, between-group differences 


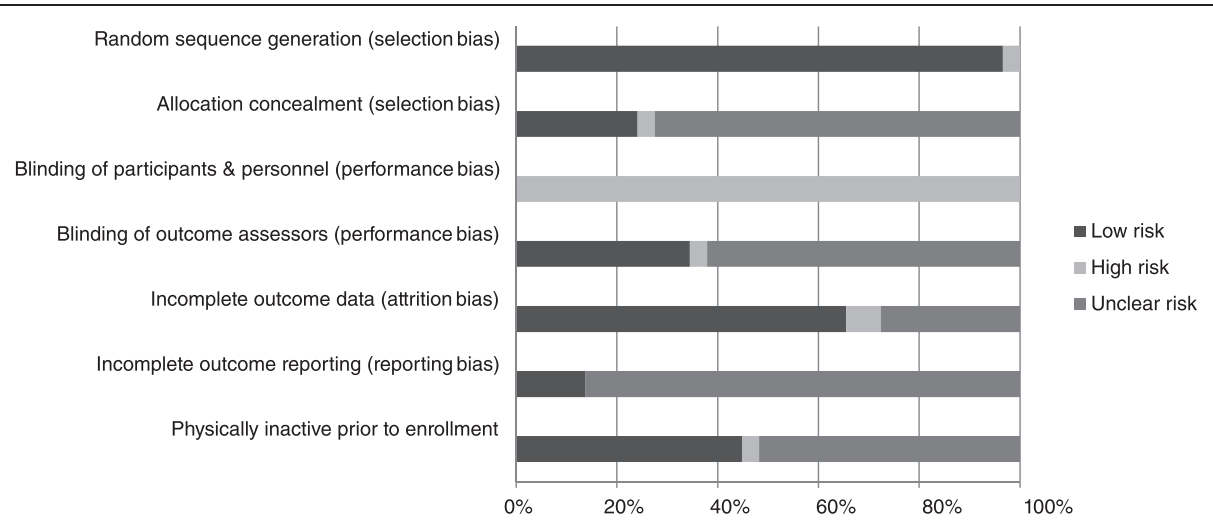

Figure 2 Risk of bias. Pooled risk of bias results using the Cochrane Risk of Bias Assessment Instrument.

were limited to gender, with women only groups experiencing greater reductions in depressive symptoms than mixed groups (no study was limited to men) and type of AORC (reductions in depressive symptoms greater in fibromyalgia versus rheumatoid arthritis participants). However, as can be seen, the results for those groups comprised of those with rheumatoid arthritis, osteoarthritis or rheumatoid arthritis and rheumatoid arthritis or systemic lupus erythematosus, were limited to three, two and one results, respectively.

Exploratory meta-regression analyses for changes in depressive symptoms and selected continuous covariates are shown in Additional file 5. As can be seen greater reductions in depressive symptoms were associated with increases in BMI $\left(R^{2}=0.90\right)$, greater reductions in pain $\left(R^{2}=\right.$
$0.21)$, improvements in quality-of-life $\left(R^{2}=0.46\right)$ and decreases in static balance $\left(R^{2}=0.81\right)$. However, the finding for static balance was limited to three effect sizes.

\section{Secondary outcomes}

Changes in secondary outcomes are shown in Table 3. As can be seen, there were no statistically significant changes in body weight, BMI in $\mathrm{kg} \mathrm{m}^{2}$, percent body fat or static balance. In contrast, a statistically significant improvement was observed for physical function. Heterogeneity was considered to be very low and nonsignificant. In addition, PI were statistically significant. Changes were equivalent to a percentile improvement of $21.9 \%$. However, statistically significant small-study effects were observed (95\% CI, 0.16 to 2.72 ). With each

Table 3 Changes in primary and secondary outcomes

\begin{tabular}{|c|c|c|c|c|c|c|c|}
\hline Variable & Studies (Number) & ES (Number) & $\begin{array}{l}\text { Participants } \\
\text { (Number) }\end{array}$ & $\bar{x}(95 \% \mathrm{Cl})$ & $\mathrm{Q}(P)$ & $I^{2}(\%)$ & $95 \% \mathrm{PI}$ \\
\hline \multicolumn{8}{|l|}{ Primary } \\
\hline - Depressive symptoms (g) & 29 & 35 & 2449 & $-0.42(-0.58,-0.26)^{*}$ & $126.9(<0.001)^{* *}$ & 73.2 & $-1.23,0.38$ \\
\hline \multicolumn{8}{|l|}{ Secondary } \\
\hline - Body weight (kg) & 3 & 3 & 226 & $-0.75(-3.25,1.74)$ & $3.1(0.21)$ & 35.2 & - \\
\hline$-\mathrm{BMI}\left(\mathrm{kg} \mathrm{m}^{2}\right)$ & 5 & 5 & 266 & $0.08(-0.19,0.36)$ & $3.0(0.55)$ & 0 & - \\
\hline - Body fat (\%) & 3 & 3 & 121 & $-0.05(-0.72,0.62)$ & $0.9(0.65)$ & 0 & - \\
\hline - Physical function ( $g$ ) & 21 & 26 & 1513 & $0.58(0.46,0.70)^{*}$ & $33.0(0.13)$ & 24.3 & $0.26,0.90^{*}$ \\
\hline - Pain $(g)$ & 25 & 30 & 1971 & $-0.57(-0.76,-0.38)^{*}$ & $119.6(<0.001)^{* *}$ & 75.7 & $-1.51,0.36$ \\
\hline - Quality-of-life (g) & 18 & 21 & 1276 & $0.73(0.53,0.92)^{*}$ & $54.0(<0.001)^{* *}$ & 62.9 & $-0.03,1.48$ \\
\hline - Anxiety (g) & 13 & 16 & 976 & $-0.63(-0.86,-0.40)^{*}$ & $47.8(<0.001)^{* *}$ & 68.6 & $-1.49,0.23$ \\
\hline$-V_{2 \max }\left(\mathrm{ml} \mathrm{kg}^{-1} \mathrm{~min}^{-1}\right)$ & 7 & 10 & 590 & $1.73(0.87,2.59)^{*}$ & $40.9(<0.001)^{* *}$ & 78.0 & $-1.21,4.67$ \\
\hline - Upper body strength (g) & 6 & 9 & 530 & $0.51(0.31,0.71)^{*}$ & $11.8(0.16)$ & 32.3 & $0.04,0.98^{*}$ \\
\hline - Lower body strength (g) & 9 & 10 & 584 & $0.83(0.49,1.12)^{*}$ & $32.1(<0.001)^{* *}$ & 72.0 & $-0.28,1.95$ \\
\hline - Balance (g) & 3 & 3 & 147 & $0.49(-0.21,1.19)$ & $8.1(0.02)$ & 75.5 & - \\
\hline
\end{tabular}

Boldfaced items indicate statistical significance. * ${ }^{*}$ statistically significant, non-overlapping $95 \%$ confidence intervals; ${ }^{*}$ statistically significant $(P \leq 0.10)$. BMI, body mass index; ES, effect size; $g$, Hedges standardized mean difference, adjusted for small-sample bias; $l^{2}(\%), I$-squared; $Q(P)$, Cochran's $Q$ statistic and alpha value for $\mathrm{Q} ; \mathrm{VO}_{2 \max }$ maximum oxygen consumption; $\bar{x}(95 \% \mathrm{Cl})$, mean and $95 \%$ confidence interval; $95 \% \mathrm{Pl}, 95 \%$ prediction intervals; -, insufficient data to calculate. 


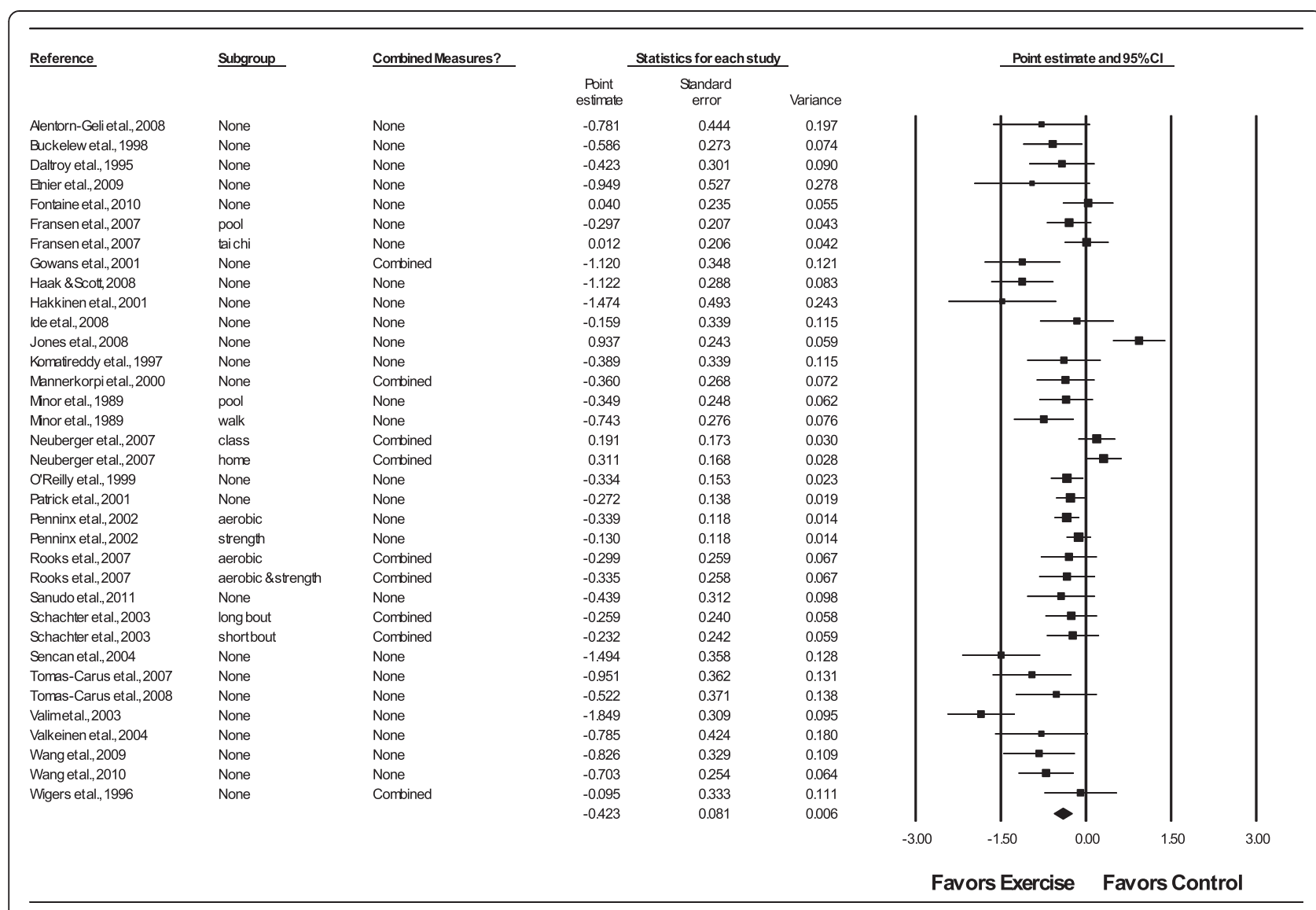

Figure 3 Forest plot for changes in depressive symptoms. Forest plot for point estimate changes in depressive symptoms. The black squares represent the mean difference while the left and right extremes of the squares represent the corresponding $95 \%$ confidence intervals. The middle of the black diamond represents the overall mean difference while the left and right extremes of the diamond represent the corresponding $95 \%$ confidence intervals. Combined measures represent those studies in which multiple assessment instruments for depression and/or per-protocol and intention-to-treat analyses were merged.

study deleted from the model once, improvements remained statistically significant, ranging from 0.55 to 0.60. Results were similar when data were collapsed so that only one result represented each study $(\bar{x}, 0.57,95 \%$ CI, 0.45 to $\left.0.70 ; \mathrm{Q}=27.8, P=0.11 ; I^{2}=28.1 \%\right)$. Cumulative meta-analysis showed that improvements in physical function have been statistically significant since the year 1989 , the year that the first included study was conducted [19].

Statistically significant decreases in pain were found with percentile reductions equivalent to $21.5 \%$. However, heterogeneity was both statistically significant and large. In addition, PI were non-significant and small-study effects were observed (95\% CI, -4.76 to -1.17 ). With each study deleted from the model once, reductions remained statistically significant, ranging from -0.52 to -0.60 . With three outliers deleted from the model [14,26,27], results remained statistically significant $(\bar{x},-0.52,95 \%$ $\mathrm{CI},-0.67$ to $\left.-0.36 ; \mathrm{Q}=66.6, P<0.001 ; I^{2}=61.0 \%\right)$.
Results were similar when data were collapsed so that only one result represented each study $(\bar{x},-0.63,95 \% \mathrm{CI},-0.83$ to $\left.-0.44 ; \mathrm{Q}=98.2, P<0.001 ; I^{2}=75.6 \%\right)$. Cumulative metaanalysis showed that results have been statistically significant since the year 1999.

Statistically significant increases in quality-of-life were also observed with percentile improvements of $26.6 \%$. Heterogeneity was considered to be statistically significant but moderate. Prediction intervals were nonsignificant while statistically significant small-study effects were observed (95\% CI, 1.67 to 4.90 ). With each study deleted from the model once, increases remained statistically significant, ranging from 0.67 to 0.76 . With two outliers deleted from the model [14,28], results remained statistically significant $(\bar{x}, 0.61,95 \% \mathrm{CI}, 0.47$ to 0.76; $\left.\mathrm{Q}=27.0, P=0.08 ; I^{2}=33.3 \%\right)$. Heterogeneity was reduced by $29.6 \%$, from moderate to low. Cumulative meta-analysis showed that improvements in quality-oflife have been statistically significant since the year 2000 . 




Figure 4 Funnel plot for changes in depressive symptoms. Small-study effects are apparently present given the lack of results in the lower right section of the funnel plot.

For anxiety, statistically significant decreases were observed along with statistically significant and moderate heterogeneity. Prediction intervals were not statistically significant and significant small-study effects were observed (95\% CI, -6.98 to -2.72 ). Decreases in anxiety were equivalent to a percentile reduction of $23.5 \%$. With each study deleted from the model once, deceases remained statistically significant, ranging from -0.56 to -0.67 . Results were similar when data were collapsed so that only one result represented each study $(\bar{x},-0.64,95 \% \mathrm{CI},-0.90$ to $-0.38 ; \mathrm{Q}=$ 46.9, $\left.\quad P<0.001 ; I^{2}=74.4 \%\right)$. Cumulative meta-analysis showed that decreases in anxiety have been statistically significant since 1989, the year that the first included study was conducted [19].

Increases in aerobic fitness, as assessed by $\mathrm{VO}_{2 \max }$ in $\mathrm{ml} \mathrm{kg}^{-1} \cdot \mathrm{min}^{-1}$, were statistically significant and equivalent to a percentile improvement of $24.5 \%$. Heterogeneity was statistically significant and large. In addition, PI were non-significant. Small-study effects were not statistically significant ( $95 \% \mathrm{CI},-5.49$ to 4.33 ). With each study deleted from the model once, increases remained statistically significant, ranging from 1.51 to $2.01 \mathrm{mlkg}^{-1}$. $\min ^{-1}$. Results were similar when data were collapsed so that only one finding represented each study $(\bar{x}, 1.62 \mathrm{ml}$. $\mathrm{kg}^{-1} \cdot \mathrm{min}^{-1}, 95 \% \mathrm{CI}, 0.57$ to $2.67 ; \mathrm{Q}=37.9, P<0.001 ; I^{2}=$ $84.2 \%)$. Cumulative meta-analysis showed that increases in $\mathrm{VO}_{2 \max }$ in $\mathrm{ml} \mathrm{kg}^{-1} \cdot \mathrm{min}^{-1}$ have been statistically significant since the year 2003 .
Changes in both upper and lower body strength were statistically significant. For upper body strength, increases were equivalent to a percentile increase of $19.5 \%$. Heterogeneity was non-significant and low. In addition, no statistically significant small-study effects were observed (95\% CI, -1.56 to 4.11 ) and PI were statistically significant. With each study deleted from the model once, increases remained statistically significant, ranging from 0.44 to 0.58 . Results were similar when data were collapsed so that only one result represented each study $(\bar{x}, 0.50,95 \% \mathrm{CI}, 0.33$ to $0.67 ; \mathrm{Q}=5.5, P=$ $\left.0.36 ; I^{2}=9.0 \%\right)$. Cumulative meta-analysis showed that increases in upper body strength have been statistically significant since the year 1989, the year that the first included study was conducted [19]. For lower body strength, increases were statistically significant and equivalent to a percentile improvement of $29.7 \%$. Heterogeneity was statistically significant but moderate. Statistically significant small-study effects were observed (95\% CI, 1.36 to 5.82) while PI were nonsignificant. With each study deleted from the model once, increases remained statistically significant, ranging from a $g$ of 0.70 to 0.91 . Results were similar when data were collapsed so that only one result represented each study $(\bar{x}, 0.81,95 \% \mathrm{CI}, 0.46$ to $1.16 ; \mathrm{Q}=28.9$, $\left.P<0.001 ; I^{2}=72.3 \%\right)$. Cumulative meta-analysis showed that increases in lower body strength have been statistically significant since the year 1999 . 




\section{Discussion}

\section{Findings}

The primary purpose of this study was to use the aggregate data meta-analytic approach to determine the effects of exercise (aerobic, strength training or both) on depressive symptoms in adults with AORC: fibromyalgia, osteoarthritis, rheumatoid arthritis and systemic lupus erythematosus. The overall findings suggest that exercise is associated with important reductions in depressive symptoms among selected adults with AORC. This interpretation is supported by: (1) non-overlapping $95 \% \mathrm{CI}$ for overall results, (2) consistency with overall results when each study was deleted from the model once (influence analysis), (3) consistency with overall results when outliers were deleted from the model (outlier analysis), (4) consistency with overall results when data were collapsed so that one result represented each study (independence analysis), (5) significance of results over the entire time period that included studies were conducted (cumulative meta-analysis), (6) low NNT and (7) number of people who could potentially benefit by initiating and maintaining a regular exercise program. Alternatively, confidence in the overall findings for depressive symptoms may be weakened by one or more of the following five factors. First, while a random-effects model that incorporates heterogeneity into the analysis was used, a moderate amount of heterogeneity, based on a fixedeffect model, was observed. This suggests that selected but unknown factors may be associated with the magnitude of change, if any, in depressive symptoms among adults with AORC. Importantly, heterogeneity in metaanalysis is not only common [71], but also relevant, as there is no need to combine studies exactly alike since their findings, within statistical error, would be the same [72]. Second, statistically significant small-study effects were observed. While publication bias is one possible 


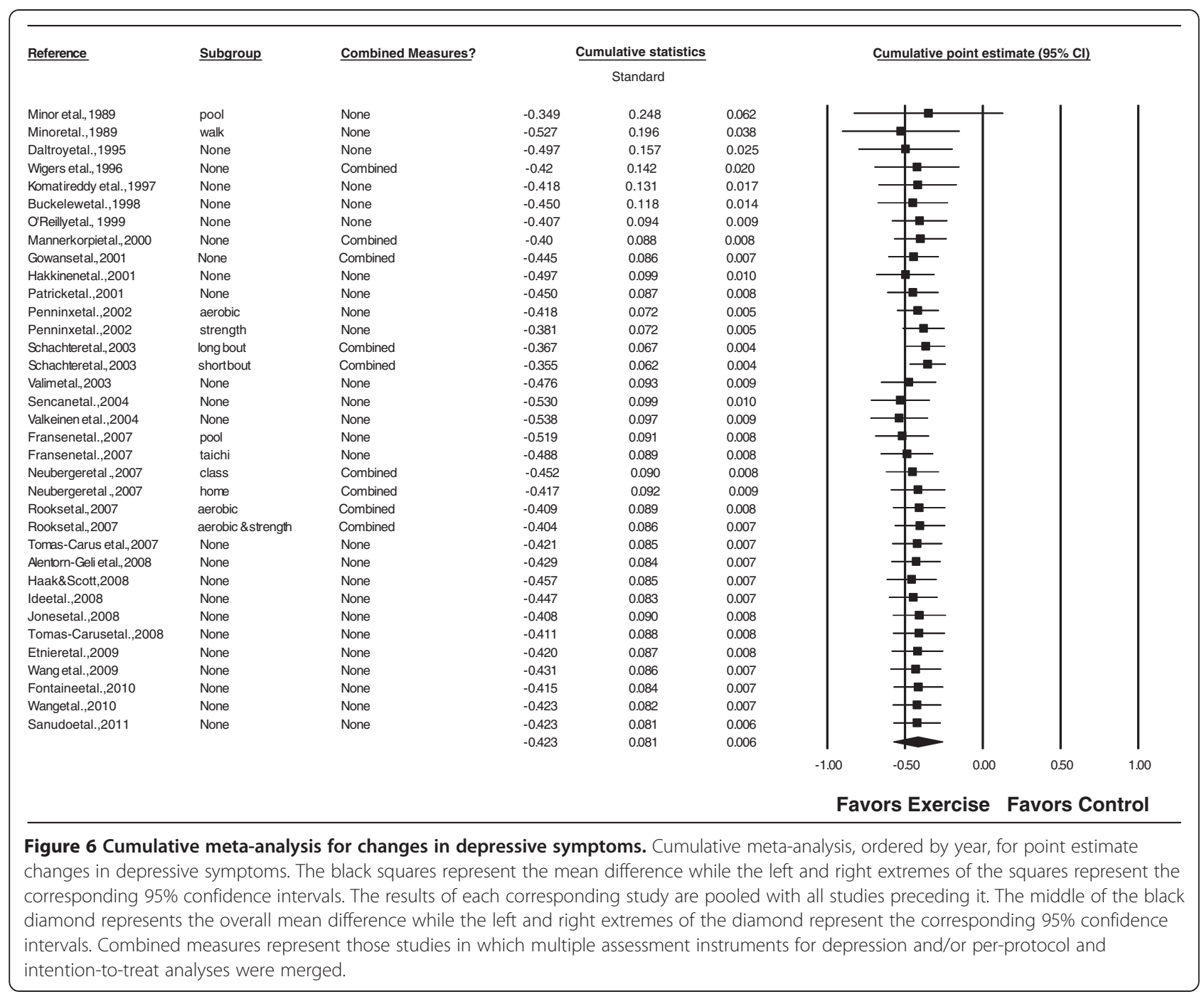

explanation for this finding, other potential factors may be at play here. These include: (1) other reporting biases (selective outcome and/or analysis reporting), (2) poor methodological quality leading to inflated effects in smaller studies, (3) true heterogeneity, (4) sampling variation leading to an association between the intervention effect and standard error and (5) chance [42]. Third, overlapping PI were observed. However, PI should not be confused with $\mathrm{CI}$ since PI are based on a random mean effect while CI are not [60]. Nevertheless, nonoverlapping PI would give one more confidence in any overall findings observed. Fourth, many of the studies were at a high or unclear risk of bias for several items from the Cochrane Risk of Bias Assessment Instrument. These include: (1) allocation concealment, (2) blinding of outcome assessors, (3) attrition, including reasons, according to each group and (4) physical activity levels of the participants prior to study enrollment. While all of the included studies were also considered to be at a high risk of bias for the blinding of participants and personnel category, it is probably impossible to blind participants to group assignment in exercise intervention studies. Therefore, the best that might be expected is to blind personnel to group assignment. Fifth, some of the differences observed for the exploratory moderator and meta-regression results suggest that selected factors may affect any overall conclusions drawn. These include, but are not necessarily limited to: (1) method used to assess depressive symptoms, (2) type of AORC, (3) exercise delivery and (4) observed associations between reductions in depressive symptoms and BMI, pain, quality of life and static balance. However, the moderator and metaregression results need to be viewed cautiously for at least three reasons. First, because of missing data for different variables from different studies, a common occurrence in meta-analysis, multiple meta-regression analysis 
was not feasible. Thus, the inability to control for relevant variables may have resulted in spurious findings for the separate analyses conducted. Second, the small sample sizes for many of the categorical analyses as well as some of the meta-regression analyses, for example, static balance, may have yielded spurious results. Third, studies are not randomly assigned to covariates in metaanalysis. Thus, they are considered to be observational in nature. Consequently, the results of moderator and meta-regression analyses conducted in any meta-analysis does not support causal inferences and should be viewed as nothing more than exploratory [66]. Large, welldesigned randomized controlled trials would be needed to address this issue adequately. Given this, future randomized controlled trials may want to address some of the differences and associations observed in the current meta-analysis.

The direction of effect for reductions in depressive symptoms found in the current meta-analysis (SMD, $-0.42,95 \% \mathrm{CI},-0.58$ to -0.26$)$ are consistent with previous meta-analytic work by Busch et al. (SMD, -0.61, $95 \% \mathrm{CI},-0.99$ to -0.23 ) [37], Hauser et al. (SMD, -0.32, 95\% CI, -0.53 to -0.12 ) [38] and Herring et al. (SMD, $0.29,95 \% \mathrm{CI},-0.16$ to -0.43 ) [39] in participants with fibromyalgia. While the overall magnitude of effect varies between all four meta-analyses, the $95 \%$ CI for all studies overlap, suggesting no statistically significant difference between them. The former notwithstanding, one possible reason for the differences in the overall magnitude of effect may have to do with the fact that the exact same studies were not included in any of these meta-analyses.

The overall magnitude of reduction for depressive symptoms observed in the current study $(g=-0.42)$ is approximately $38.1 \%$ greater than that reported in a previous meta-analysis of pharmacologic interventions limited to participants with fibromyalgia [73]. Hauser et al. examined the effects of tricyclic and tetracyclic antidepressants, selective serotonin reuptake inhibitors, serotonin and noradrenaline reuptake inhibitors and monoamine oxidase inhibitors on depressed mood in 18 studies representing 1,427 participants [73]. Overall, a statistically significant decrease in depressed mood was observed, (standardized mean difference reduction, -0.26 ; ( $95 \% \mathrm{CI},-0.39$ to -0.12 ) [73]. However, as opposed to the current meta-analysis, no statistical heterogeneity was observed $\left(I^{2}=0 \%\right)$ [73]. In addition, the confidence intervals between the current meta-analysis and the Hauser et al. [73] meta-analysis are overlapping.

In addition to statistically significant reductions in depressive symptoms, improvements were also observed for physical function, pain, quality-of-life, anxiety, $\mathrm{VO}_{2 \max }$ in $\mathrm{ml} \mathrm{kg}^{-1} \mathrm{~min}^{-1}$, and upper and lower body strength. As opposed to pharmacologic interventions that generally target one outcome, these findings provide evidence to support the use of exercise for improving multiple outcomes. This notwithstanding, the findings for these secondary outcomes need to be interpreted with caution given that they were only included if depressive symptoms was included as an outcome. Consequently, the data from which these results were derived may represent a biased sample.

\section{Implications for research}

The results of the current systematic review with metaanalysis have at least seven implications for the reporting and conduct of future randomized controlled trials. First, based on the Cochrane Risk of Bias Assessment Instrument [49], it is recommended that future randomized controlled trials on the effects of exercise in adults with AORC improve their reporting with respect to several potential sources of bias. These include; (1) allocation concealment, (2) blinding of outcome assessors, (3) attrition, including reasons, according to each group and (4) the physical activity levels of the participants prior to study enrollment. While all of the included studies were also considered to be at a high risk of bias for the blinding of participants and personnel category, it is probably impossible to blind participants to group assignment in exercise intervention studies. Therefore, the best that might be expected is to blind personnel to group assignment.

Second, only four studies used both the per-protocol and intention-to-treat approach in the analysis of their data $[12,24,26,34]$. Given this, it is suggested that future studies include both in order to gain a better understanding regarding the efficacy and effectiveness of exercise for improving depressive symptoms in adults with AORC [74].

Third, very little data were available for adverse events as well as the cost-effectiveness of the interventions employed. Since these are important factors to consider when making decisions regarding the choice of one intervention over another, it is suggested that future studies collect and report this information.

Fourth, complete information should be collected and reported on the exercise intervention(s) employed. For example, in the current meta-analysis, data on the intensity of exercise as well as compliance with the exercise intervention were underreported. More specifically, future studies should report complete information on the length, frequency, intensity and duration of exercise, mode(s) used, and compliance with the exercise protocol. Also, information on the setting in which exercise takes place as well as supervision status should be reported. Because of the potential for physical activity compensation to occur [75], data should also be collected and reported on total physical activity for all groups included in the study. The rationale for this suggestion is based on the possibility that physical activity 
levels beyond any intervention(s) may increase or decrease in the intervention and/or control groups. For example, two of the included studies reported that exercise participants increased their physical activity beyond the exercise intervention $[10,25]$. Increases or decreases such as these may negatively impact the results of one or more outcomes and may be especially problematic when trying to address the issue of dose-response.

Fifth, since the dose-response effects of exercise on depressive symptoms in adults with AORC are not known, it is suggested that future randomized controlled trials address this issue. The determination of such is critical for the development of optimal exercise programs for improving depressive symptoms in adults with AORC. Along those lines and as previously mentioned, it would appear plausible to suggest that an examination of some of the differences and associations observed in the current meta-analysis would be appropriate. For example, if feasible, a multi-arm, randomized controlled exercise intervention trial that includes participants with different types of AORC may be appropriate.

Sixth, while fourteen of the included studies were limited to women $[6,9,13-15,18,24-31]$ and fifteen were mixed [7,8,10-12,16,17,19-23,32-34], none were limited to men. Given that the age-adjusted prevalence of doctor-diagnosed arthritis in the US has been reported to be $18.6 \%$ in men and that the biology between men and women differs, future studies limited to men or that include both men and women with results partitioned according to sex, seem appropriate.

Seventh, since no study was limited to participants with systemic lupus erythematosus and only two were limited to adults with rheumatoid arthritis $[17,20]$, future exercise intervention studies may want to focus on these populations. Such a focus may allow one to draw more definitive conclusions regarding the effects of exercise on depressive symptoms in these specific populations.

In addition to the reporting and conduct of future randomized controlled trials, the current meta-analysis provides at least three implications for future systematic reviews with meta-analysis. First, the a priori plan of the current study was to conduct a one-step IPD metaanalysis [51]. Nevertheless, because of: (1) the ability to obtain IPD from only $24.1 \%$ of eligible studies, (2) the inability to resolve discrepancies between the IPD provided and data reported in the published studies, for example, final sample sizes, and (3) the potential loss of power with fewer included studies, a post hoc decision was made to conduct an aggregate data meta-analysis, an approach similar to conducting a two-step metaanalysis with IPD [51]. While IPD meta-analysis is considered by some to be the gold standard [51,76], primarily because of the potential to conduct covariate analyses at the participant level, this has to be considered with respect to obtaining IPD from all eligible studies. In addition, causal inferences based on covariate analyses, whether conducted using IPD or aggregate data, cannot be made given that experiments are never randomly assigned to covariates [66,77]. Furthermore, the time and costs associated with conducting an IPD metaanalysis have been shown to be substantially greater than conducting an aggregate data meta-analysis. For example, in 1997, Steinberg et al. estimated the cost for 12 ovarian cancer studies to be $\$ 259,300$ for conducting an IPD meta-analysis versus $\$ 48,665$ for an aggregate data meta-analysis [78]. However, this 5.3 times greater cost has been suggested by others to be 8 times greater since the research team continued to work on the project after funding ended [77]. Importantly, the use of IPD is not always well established. To illustrate, when examining overall effects, the primary purpose of meta-analysis [72], studies claiming the superiority of IPD have been based on comparisons of a different number of studies between IPD and aggregate data [79,80]. However, when an indistinguishable or a nearly indistinguishable number of studies were included, the overall results were found to be analogous $[78,81,82]$. Finally, despite the increased use of IPD in recent years [83], the aggregate data approach is still the most frequently used when conducting a meta-analysis. Given this, future investigators planning a meta-analysis should think very carefully about the feasibility and potential gain derived from conducting an IPD versus aggregate data meta-analysis.

Second, given that the secondary outcomes included in the current meta-analysis may represent a biased sample, future meta-analytic work that includes one or more of these as a primary outcome might be important. For example, recent research has shown that the prevalence of anxiety among US adults was approximately twice as high as depression (30.5\% versus $17.5 \%$ ), with US population estimates of 11.5 million for anxiety and 6.6 million for depression [4]. However, a previous systematic review by the first two authors did not identify any previous systematic reviews with meta-analysis that met their inclusion criteria with respect to the effects of exercise on anxiety in adults with AORC (unpublished results). Given the reductions observed for anxiety in the current meta-analysis, it is suggested that a full systematic review with meta-analysis that includes anxiety as a primary outcome is warranted.

Third, the ultimate goal in the treatment of any condition is the identification of what treatments work best, that is, comparative effectiveness research. However, it is highly unlikely that any large multi-arm randomized controlled trial will ever be conducted that includes all possible pharmacologic and non-pharmacologic interventions that address the effects of depressive symptoms 
in adults with AORC. Alternatively, one cost-effective approach is the use of network meta-analysis, an increasingly popular method that allows one to incorporate both direct and indirect evidence in decisions about which treatment works best $[84,85]$. To the best of the investigative team's knowledge, no such study exists with respect to depressive symptoms in adults with AORC.

\section{Implications for practice}

The results of the current meta-analysis in adults with AORC have relevant implications for practice. Overall, it appears that exercise may improve depressive symptoms as well as a number of other outcomes (physical function, pain, quality-of-life, anxiety, $\mathrm{VO}_{2 \max }$ in $\mathrm{ml} \mathrm{kg}^{-1} \mathrm{~min}^{-1}$ and strength) in selected adults with AORC. Given this and despite the fact that no dose-response effects of exercise on depressive symptoms were identified and there was a lack of reporting for adverse events and cost-effectiveness, it would appear plausible to suggest that exercise might be a valuable addition to the treatment of adults with AORC. While such programs may need to be individually tailored to each person's specific condition, following the general guidelines recommended by the US Centers for Disease Control and Prevention in adults with arthritis may be an appropriate starting point, especially if viewed from a community-based, public health perspective [86]. This includes 150 minutes per week of moderate-intensity aerobic activity, for example, brisk walking, 75 minutes per week of vigorousintensity aerobic activity, for example, water aerobics, or some equivalent combination of both moderate and vigorous-intensity activity [86]. In addition, muscle strengthening exercises using equipment such as resistance bands is recommended on two or more days per week as well as balance exercises, for example, standing on one foot, at least three days per week [86]. When initiating an exercise program, it is suggested that participants with AORC: (1) start with activity performed over a short duration and at a low intensity, (2) modify one's activity when arthritis symptoms increase, (3) participate in activities that do not place undue stress on the joints, for example, swimming versus running, (4) exercise in environments that are safe, and (5) seek guidance from a healthcare professional or certified exercise specialist [86].

\section{Strengths and limitations of current study Strengths}

There are least four potential strengths of the current meta-analysis. First, to the best of the investigative team's knowledge, this is the first meta-analysis to examine the effects of exercise on depressive symptoms as a primary outcome in adults with AORC beyond those with fibromyalgia [36]. Thus, this adds important information as well as direction for future research and practical application regarding the effects of exercise on depressive symptoms in adults with AORC. Second, the inclusion of the NNT provides practical information to aid decision-makers in deciding what treatments to recommend or prioritize over others when attempting to reduce depressive symptoms in adults with AORC. Third, gross estimates of the number of US adults with AORC who might reduce their depressive symptoms by participating in a regular exercise program can help aid decision-makers and others in allocating the resources necessary for increasing exercise in this population. Fourth, the calculation and inclusion of PI can aid researchers when planning future randomized controlled trials on this topic.

\section{Limitations}

The results of the current meta-analysis should be viewed with respect to the following five potential limitations. First, a large number of statistical tests were conducted but no adjustments were made for multiple testing because of the concern about missing possibly important findings that could be pursued in future randomized controlled trials [87]. While this may be viewed by some as a 'fishing expedition', the investigative team felt that these pre-planned analyses were important for providing investigators with potential direction for $\mathrm{fu}$ ture randomized controlled trials. Nevertheless, some statistically significant results observed may have been chance findings. Second, the sample sizes for many of the analyses were small and, thus, probably underpowered to find a true effect or difference. In addition, the generalizability of results based on these small sample sizes is questionable. Third, given the different assessment instruments used as well as a lack of information provided on the severity of depressive symptoms upon study entry, the investigative team was unable to assess accurately whether greater decreases might be achieved by those with greater depressive symptoms at baseline. Fourth, the weaknesses and limitations of the studies included in any meta-analysis are inherited by the metaanalysis itself and, thus, may have a deleterious effect on any findings and conclusions drawn. Fifth, like any meta-analysis, the results of the current investigation may be prone to ecological fallacy and/or Simpson's Paradox [77].

\section{Conclusions}

Exercise is associated with decreases in depressive symptoms among selected adults with AORC. A need exists for additional, well-designed and reported randomized controlled trials on this topic. 


\section{Additional files}

Additional file 1: Search strategy for Scopus database. This file provides the search strategy used for the Scopus database.

Additional file 2: Excluded studies, including reasons. This file provides a reference list of all excluded studies, including the reasons for exclusion.

Additional file 3: Cochrane risk of bias results for each item from each included study. This file provides an item analysis, by study, of the risk for bias using the Cochrane Risk of Bias Assessment Instrument.

Additional file 4: Table of categorical analyses results for changes in depressive symptoms. This file provides a table of all moderator analyses conducted.

Additional file 5: Mixed effects meta-regression results for changes in depressive symptoms. This file provides a table of all meta-regression analyses conducted.

\section{Abbreviations}

AORC: arthritis and other rheumatic conditions; BMl: body mass index; Cl: confidence intervals; CINAHL: Cumulative Index of Nursing and Allied Health Literature; NNR: number needed to read; NNT: number-needed-to-treat; PEDro: Physiotherapy evidence database; PI: prediction intervals; SMD: standardized mean difference; US: United States; $\mathrm{VO}_{2 \text { max: }}$ maximum oxygen consumption.

\section{Competing interests}

The authors declare that they have no competing interests.

\section{Authors' contributions}

GAK was responsible for the conception and design, acquisition of data, analysis and interpretation of data, drafting the initial manuscript and revising it critically for important intellectual content. KSK was responsible for the conception and design, acquisition of data, drafting the initial manuscript, and revising all drafts critically for important intellectual content. $\mathrm{JMH}$ was responsible for the conception and design, acquisition of data, drafting the initial manuscript, and revising all drafts critically for important intellectual content. All authors read and approved the final manuscript

\section{Authors' information}

GAK has more than 20 years of successful experience in the design and conduct of all aspects of meta-analysis, including the effects of chronic exercise in adults with arthritis and other rheumatic disease. KSK has more than 16 years of successful experience in conducting meta-analysis, including the effects of chronic exercise in adults with arthritis and other rheumatic disease. JMH has more than 20 years of successful experience that includes expertise in interventions, including exercise, designed to treat adults with arthritis and other rheumatic disease.

\section{Acknowledgments}

The authors would like to thank Ms. Jean Siebert, MBA, MA, West Virginia University Health Sciences Library, for conducting all database searches. The authors would also like to thank the following people for supplying us with individual participant data: Susan Buckelew, Jennifer L. Etnier, Marlene Fransen, A. Hakkinen, Geri B. Neuberger, Sheila C. O'Reilly, Michael Doherty, Joanna Romawski, Mike E. Miller, Brenda Penninx, William B. Applegate, Candace L. Schachter, Ayse Karan, Sureyya Sencan, Jamil Natour, Valerie Valim, and H. Valkeinen. The research reported in this manuscript was supported by the National Institute of Arthritis and Musculoskeletal and Skin Diseases of the National Institutes of Health under award number RO1AR061346 (GAK, Principal Investigator) and the National Institute of General Medical Sciences of the National Institutes of Health under award number U54GM104942. The content is solely the responsibility of the authors and does not necessarily represent the official views of the National Institutes of Health or the Centers for Disease Control and Prevention.

\section{Author details}

'Department of Biostatistics, Robert C. Byrd Health Sciences Center, School of Public Health, West Virginia University, Morgantown, WV 26506-9190, USA. ${ }^{2}$ Division of Population Health MS F-78, National Center for Chronic Disease Prevention and Health Promotion, Centers for Disease Control and Prevention Atlanta, Atlanta, GA 30341, USA.
Received: 22 July 2014 Accepted: 19 January 2015

Published online: 03 February 2015

\section{References}

1. Barbour KE, Helmick CG, Theis KA, Murphy LB, Hootman JM, Brady TJ, et al. Prevalence of doctor-diagnosed arthritis and arthritis-attributable activity limitation - United States, 2010-2012. Morb Mortal Wkly Rep. 2013;62:869-73.

2. Hootman JM, Helmick CG. Projections of US prevalence of arthritis and associated activity limitations. Arthritis Rheum. 2006;54:226-9.

3. Yelin E, Murphy L, Cisternas MG, Foreman AJ, Pasta DJ, Helmick CG. Medical care expenditures and earnings losses among persons with arthritis and other rheumatic conditions in 2003, and comparisons with 1997. Arthritis Rheum. 2007:56:1397-407.

4. Murphy LB, Sacks JJ, Brady TJ, Hootman JM, Chapman DP. Anxiety and depression among US adults with arthritis: prevalence and correlates. Arthritis Care Res. 2012;64:968-76.

5. Shih M, Hootman JM, Kruger J, Helmick CG. Physical activity in men and women with arthritis National Health Interview Survey, 2002. Am J Prev Med. 2006;30:385-93.

6. Alentorn-Geli E, Padilla J, Moras G, Lazaro HC, Fernandez-Sola J. Six weeks of whole-body vibration exercise improves pain and fatigue in women with fibromyalgia. J Altern Complement Med. 2008;14:975-81.

7. Buckelew SP, Conway R, Parker J, Deuser WE, Read J, Witty TE, et al. Biofeedback/relaxation training and exercise interventions for fibromyalgia: a prospective trial. Arthritis Rheum. 1998;11:196-209.

8. Daltroy LH, Robb-Nicholson C, Iversen MD, Wright EA, Liang MH. Effectiveness of minimally supervised home aerobic training in patients with systemic rheumatic disease. Br J Rheumatol. 1995;34:1064-9.

9. Etnier JL, Karper WB, Gapin JI, Barella LA, Chang YK, Murphy KJ. Exercise, fibromyalgia, and fibrofog: a pilot study. J Phys Act Health. 2009;6:239-46.

10. Fontaine KR, Conn L, Clauw DJ. Effects of lifestyle physical activity on perceived symptoms and physical function in adults with fibromyalgia: results of a randomized trial. Arthritis Res Ther. 2010;12:R55.

11. Fransen M, Nairn L, Winstanley J, Lam P, Edmonds J. Physical activity for osteoarthritis management: a randomized controlled clinical trial evaluating hydrotherapy or Tai Chi classes. Arthritis Rheum. 2007;57:407-14.

12. Gowans SE. deHueck A, Voss S, Silaj A, Abbey SE, Reynolds WJ. Effect of a randomized, controlled trial of exercise on mood and physical function in individuals with fibromyalgia. Arthritis Rheum. 2001;45:519-29.

13. Haak T, Scott B. The effect of Qigong on fibromyalgia (FMS): a controlled randomized study. Disabil Rehabil. 2008;30:625-33.

14. Hakkinen A, Hakkinen K, Hannonen P, Alen M. Strength training induced adaptations in neuromuscular function of premenopausal women with fibromyalgia: comparison with healthy women. Ann Rheum Dis. 2001;60:21-6.

15. Ide MR, Laurindo IM, Rodrigues AL, Tanaka C. Effect of aquatic respiratory exercise-based program in patients with fibromyalgia. Int J Rhuem Dis. 2008;11:131-40.

16. Jones KD, Burckhardt CS, Deodhar AA, Perrin NA, Hanson GC, Bennett RM. A six-month randomized controlled trial of exercise and pyridostigmine in the treatment of fibromyalgia. Arthritis Rheum. 2008;58:612-22.

17. Komatireddy GR, Leitch RW, Cella K, Browning G, Minor M. Efficacy of low load resistive muscle training in patients with rheumatoid arthritis functional class II and III. J Rheumatol. 1997;24:1531-9.

18. Mannerkorpi K, Nyberg B, Ahlmen M, Ekdahl C. Pool exercise combined with an education program for patients with fibromyalgia syndrome. A prospective, randomized study. J Rheumatol. 2000;27:2473-81.

19. Minor MA, Hewett JE, Webel RR, Anderson SK, Kay DR. Efficacy of physical conditioning exercise in patients with rheumatoid arthritis and osteoarthritis. Arthritis Rheum. 1989;32:1396-405.

20. Neuberger GB, Aaronson LS, Gajewski B, Embretson SE, Cagle PE, Loudon JK, et al. Predictors of exercise and effects of exercise on symptoms, function, aerobic fitness, and disease outcomes of rheumatoid arthritis. Arthritis Rheum. 2007;57:943-52.

21. O'Reilly SC, Muir KR, Doherty M. Effectiveness of home exercise on pain and disability from osteoarthritis of the knee: a randomised controlled trial. Ann Rheum Dis. 1999;58:15-9.

22. Patrick DL, Ramsey SD, Spencer AC, Kinne S, Belza B, Topolski TD. Economic evaluation of aquatic exercise for persons with osteoarthritis. Med Care. 2001;39:413-24.

23. Penninx BW, Rejeski WJ, Pandya J, Miller ME, Di BM, Applegate WB, et al. Exercise and depressive symptoms: a comparison of aerobic and resistance 
exercise effects on emotional and physical function in older persons with high and low depressive symptomatology. J Gerontol B Psychol Sci Soc Sci. 2002:57:124-32.

24. Rooks DS, Gautam S, Romeling M, Cross ML, Stratigakis D, Evans B, et al. Group exercise, education, and combination self-management in women with fibromyalgia: a randomized trial. Arch Intern Med. 2007;167:2192-200.

25. Sanudo B, Galiano D, Carrasco L, de Hoyo M, McVeigh JG. Effects of a prolonged exercise program on key health outcomes in women with fibromyalgia: a randomized controlled trial. J Rehabil Med. 2011;43:521-6.

26. Schachter CL, Busch AJ, Peloso PM, Sheppard MS. Effects of short versus long bouts of aerobic exercise in sedentary women with fibromyalgia: a randomized controlled trial. Phys Ther. 2003;83:340-58.

27. Sencan S, Ak S, Karan A, Muslumanoglu L, Ozcan E, Berker E. A study to compare the therapeutic efficacy of aerobic exercise and paroxetine in fibromyalgia syndrome. J Back Musculoskelet Rehabil. 2004;17:57-61.

28. Tomas-Carus P, Gusi N, Leal A, Garcia Y, Ortega-Alonso A. The fibromyalgia treatment with physical exercise in warm water reduces the impact of the disease on female patients' physical and mental health. Rheumatol Clin. 2007;3:33-7.

29. Tomas-Carus P, Gusi N, Hakkinen A, Hakkinen K, Leal A, Ortega-Alonso A. Eight months of physical training in warm water improves physical and mental health in women with fibromyalgia: a randomized controlled trial. J Rehabil Med. 2008:40:248-52.

30. Valim V, Oliveira L, Suda A, Silva L, de Assis M, Barros NT, et al. Aerobic fitness effects in fibromyalgia. J Rheumatol. 2003;30:1060-9.

31. Valkeinen $\mathrm{H}$, Alen $\mathrm{M}$, Hannonen $\mathrm{P}$, Hakkinen A, Airaksinen $\mathrm{O}$, Hakkinen $\mathrm{K}$. Changes in knee extension and flexion force, EMG and functional capacity during strength training in older females with fibromyalgia and healthy controls. Rheumatol. 2004;43:225-8.

32. Wang C, Schmid CH, Hibberd PL, Kalish R, Roubenoff R, Rones R, et al. Tai Chi is effective in treating knee osteoarthritis: a randomized controlled trial. Arthritis Rheum. 2009;61:1545-53.

33. Wang C, Schmid CH, Rones R, Kalish R, Yinh J, Goldenberg DL, et al. A randomized trial of tai chi for fibromyalgia. N Engl J Med. 2010;363:743-54.

34. Wigers SH, Stiles TC, Vogel PA. Effects of aerobic exercise versus stress management treatment in fibromyalgia. A 4.5 year prospective study. Scan J Rheumatol. 1996;25:77-86.

35. Hedges LV, Olkin I. Vote-counting methods in research synthesis. Psychol Bull. 1980;88:359-69.

36. Kelley GA, Kelley KS. Effects of exercise on depressive symptoms in adults with arthritis and other rheumatic disease: a systematic review of meta-analyses. BMC Musculoskelet Disord. 2014;15:121.

37. Busch AJ, Barber KA, Overend TJ, Peloso PM, Schachter CL. Exercise for treating fibromyalgia syndrome. Cochrane Database Syst Rev. 2007:4:CD003786.

38. Hauser W, Klose P, Langhorst J, Moradi B, Steinbach M, Schiltenwolf M, et al. Efficacy of different types of aerobic exercise in fibromyalgia syndrome: a systematic review and meta-analysis of randomised controlled trials. Arthritis Res Ther. 2010;12:R79.

39. Herring MP, Puetz TW, O'Connor PJ, Dishman RK. Effect of exercise training on depressive symptoms among patients with a chronic illness: a systematic review and meta-analysis of randomized controlled trials. Arch Int Med. 2012;172:101-11.

40. Brady TJ, Jernick SL, Hootman JM, Sniezek JE. Public health interventions for arthritis: expanding the toolbox of evidence-based interventions. J Womens Health (Larchmt). 2009:18:1905-17.

41. Conn VS. Depressive symptom outcomes of physical activity interventions: meta-analysis findings. Ann Behav Med. 2010;39:128-38.

42. Sterne JA, Sutton AJ, loannidis JP, Terrin N, Jones DR, Lau J, et al. Recommendations for examining and interpreting funnel plot asymmetry in meta-analyses of randomised controlled trials. BMJ. 2011;343:d4002.

43. van Driel ML, DeSutter A, DeMaeseneer J, Christiaens T. Searching for unpublished trials in Cochrane reviews may not be worth the effort. J Clin Epidemiol. 2009:62:838-44.

44. Waggoner CD, LeLieuvre RB. A method to increase compliance to exercise regimens in rheumatoid arthritis patients. J Behav Med. 1981:4:191-201.

45. Lee E, Dobbins M, DeCorby K, Mcrae L, Tirilis D, Husson H. An optimal search filter for retrieving systematic reviews and meta-analyses. BMC Med Res Methodol. 2012;12:51.

46. Reference Manager. (12.0.3). 2009. Philadelphia: Thompson ResearchSoft.

47. Microsoft Excel. (2007). 2007. Redmond, WA: Microsoft Corporation.
48. Cohen J. Weighted kappa: nominal scale agreement with provision for scaled disagreement or partial credit. Psychol Bull. 1968;70:213-20.

49. Higgins JP, Altman DG, Gotzsche PC, Juni P, Moher D, Oxman AD, et al. The Cochrane Collaboration's tool for assessing risk of bias in randomised trials. BMJ. 2011;343:d5928.

50. Ahn S, Becker BJ. Incorporating quality scores in meta-analysis. J Educ Behav Stat. 2011;36:555-85.

51. Riley RD, Lambert PC, Staessen JA, Wang J, Gueyffier F, Thijs L, et al. Meta-analysis of continuous outcomes combining individual patient data and aggregate data. Stat Med. 2008;27:1870-93.

52. Follmann D, Elliot $P$, Suh I, Cutler J. Variance imputation for overviews of clinical trials with continuous response. J Clin Epidemiol. 1992:45:769-73.

53. Hedges LV, Olkin I. Statistical methods for meta-analysis. San Diego, CA: Academic Press; 1985.

54. Dersimonian R, Laird N. Meta-analysis in clinical trials. Control Clin Trials. 1986;7:177-88

55. Higgins JP, Green S. Cochrane Handbook for Systematic Reviews of Interventions Version 5.1.0 [updated March 2011]. 2011. The Cochrane Collaboration. Available from www.cochrane-handbook.org.

56. Sonawalla SB, Rosenbaum JF. Placebo response in depression. Dialogues Clin Neurosci. 2002;4:105-13.

57. Cohen J. Statistical power analysis for the behavioral sciences. New York: Academic Press; 1988.

58. Durlak JA. How to select, calculate, and interpret effect sizes. J Pediatr Psychol. 2009;34:917-28.

59. Higgins JP, Thompson SG, Deeks JJ, Altman DG. Measuring inconsistency in meta-analyses. BMJ. 2003;327:557-60.

60. Higgins JP, Thompson SG, Spiegelhalter DJ. A re-evaluation of randomeffects meta-analysis. J R Stat Soc Ser A. 2009;172:137-59.

61. Kelley GA, Kelley KS. Impact of progressive resistance training on lipids and lipoproteins in adults: another look at a meta-analysis using prediction intervals. Prev Med. 2009:49:473-5.

62. Egger M, Davey Smith G, Schneider M, Minder C. Bias in meta-analysis detected by a simple graphical test. BMJ. 1997;315:629-34.

63. Lau J, Schmid CH, Chalmers TC. Cumulative meta-analysis of clinical trials builds evidence for exemplary medical care: The Potsdam International Consultation on Meta-Analysis. J Clin Epidemiol. 1995:48:45-57.

64. Borenstein M, Hedges L, Higgins J, Rothstein H. Introduction to meta-analysis. West Sussex: John Wiley \& Sons; 2009.

65. Nieman DC. Exercise testing and prescription: a health-related approach. Mayfield: Mountain View, CA; 1999.

66. Littell JH, Corcoran J, Pillai V. Systematic reviews and meta-analysis. New York: Oxford University Press; 2008

67. Biostat. Comprehensive meta-analysis. (2.2). Englewood, NJ: Biostat, Inc; 2006.

68. Microsoft Corporation. Microsoft Excel. (2010). Redmond, WA;2010.

69. Statistical Services Center. SSC-Stat. (2.18). University of Reading, UK Statistical Services Center; 2007

70. Poynton TA. EZ Analyze. (3.0). 2007. Available from: http://www.ezanalyze.com/

71. Engels EA, Schmid CH, Terrin N, Olkin I, Lau J. Heterogeneity and statistical significance in meta-analysis: an empirical study of 125 meta-analyses. Stat Med. 2000;19:1707-28.

72. Glass GV, McGaw B, Smith ML. Meta-analysis in Social Research. Newbury Park, CA: Sage; 1981.

73. Hauser W, Bernardy K, Uceyler N, Sommer C. Treatment of fibromyalgia syndrome with antidepressants: a meta-analysis. JAMA. 2009;301:198-209.

74. Katz MH. Multivariable analysis: a practical guide for clinicians. New York: Cambridge University Press; 2011.

75. Melanson EL, Keadle SK, Donnelly JE, Braun B, King NA. Resistance to exercise-induced weight loss: compensatory behavioral adaptations. Med Sci Sports Exerc. 2013;45:1600-9.

76. Kovalchik SA. Aggregate-data estimation of an individual patient data linear random effects meta-analysis with a patient covariate-treatment interaction term. Biostatistics. 2012;14:273-83.

77. Cooper H, Patall EA. The relative benefits of meta-analysis conducted with individual participant data versus aggregated data. Psychol Methods. 2009;14:165-76.

78. Steinberg KK, Smith SJ, Stroup DF, Olkin I, Lee NC, Williamson GD, et al. Comparison of effect size estimates from a meta-analysis of summary data from published studies and from a meta-analysis using individual patient data for ovarian cancer studies. Am J Epidemiol. 1997;145:917-25. 
79. Stewart LA, Parmar MK. Meta-analysis of the literature or of individual patient data: is there a difference? Lancet. 1993;341:418-22.

80. Jeng GT, Scott JR, Burmeister LF. A comparison of meta-analytic results using literature vs individual patient data. Paternal cell immunization for recurrent miscarriage. JAMA. 1995;274:830-6.

81. Olkin I, Sampson A. Comparison of meta-analysis versus analysis of variance of individual patient data. Biometrics. 1998;54:317-22.

82. Mathew T, Nordstrom K. On the equivalence of meta-analysis using literature and using individual patient data. Biometrics. 1999;55:1221-3.

83. Riley RD, Lambert PC, Abo-Zaid G. Meta-analysis of individual participant data: rationale, conduct, and reporting. BMJ. 2010;340:c221.

84. Cipriani A, Higgins JP, Geddes JR, Salanti G. Conceptual and technical challenges in network meta-analysis. Ann Int Med. 2013;159:130-7.

85. Achana F, Hubbard S, Sutton A, Kendrick D, Cooper N. An exploration of synthesis methods in public health evaluations of interventions concludes that the use of modern statistical methods would be beneficial. J Clin Epidemiol. 2014:67:376-90.

86. Centers for Disease Control and Prevention. Physical Activity for Arthritis Fact Sheet. Centers for Disease Control and Prevention; 2014.

87. Rothman KJ. No adjustments are needed for multiple comparisons. Epidemiol. 1990;1:43-6.

\section{Submit your next manuscript to BioMed Central and take full advantage of:}

- Convenient online submission

- Thorough peer review

- No space constraints or color figure charges

- Immediate publication on acceptance

- Inclusion in PubMed, CAS, Scopus and Google Scholar

- Research which is freely available for redistribution 